\title{
Experimental investigation on the bond behavior of a compatible TRM-based solution for rammed earth heritage
}

\author{
Antonio Romanazzi, Daniel V. Oliveira, Rui A. Silva \\ ISISE, Institute of Science and Innovation for Bio-Sustainability (IB-S), Department of Civil \\ Engineering, University of Minho, Guimarães, Portugal.
}

\begin{abstract}
Despite the current awareness of the high seismic risk of earthen structures, little has been done so far to develop proper strengthening solutions for the rammed earth heritage. Based on the effectiveness of TRM for masonry buildings, the strengthening of rammed earth walls with externally bonded fibers using earth-based mortar is being proposed as a compatible solution. In this context, the investigation of bond behavior was conducted by means of direct tensile tests, pull-out tests and single lap-shear tests. The specimens were prepared using earthbased mortars and two different types of meshes (glass and nylon), while considering different bonded lengths. The direct tensile tests on TRM coupons showed the high capacity of the nylon mesh in transferring stresses after cracking of the mortar. The pull-out tests highlighted that in the case of glass fiber mesh, the bond was granted by friction, while the mechanical anchorage promoted by the transversal yarns granted the bond of the nylon mesh. Finally, the single lapshear tests showed that the adopted earth-based mortar seems to limit the performance of the strengthening
\end{abstract}

Keywords: rammed earth, compatible strengthening, textile reinforced mortar, direct tensile test, pull-out test, single lap-shear test, bonded length. 


\section{Introduction}

Raw earth is one of the most ancient building materials and its related building techniques are spread worldwide. In fact, about between $20 \%$ and $33 \%$ of the global population is estimated to live in earthen constructions, while about $10 \%$ of UNESCO World Heritage is built with earth [1][2][3]. The different building techniques based on the use of raw earth were developed by different cultures depending on the locally available materials, the type of earth and the background knowledge. Hence, as an example, it is possible to identify the use of adobe in the Latin-America region, in the Mediterranean basin, in Africa and part of Middle-East and Oriental countries [4][5][6]; as well as the rammed earth technique, which was used by several cultures since ancient times [1][7]. For instance, the Great Wall of China, the Horyuji Temple in Japan or the Alhambra fortress and the Paderne Castle in the Iberian Peninsula included rammed earth walls built over the last twenty centuries [8][9]. Rammed earth (or "taipa" in Portugal, "pise”" in France or "terra compressa" in Italy) is a building technique where a mixture of moistened earth is compacted within a formwork [1]. The formwork was directly supported on the wall and it was moved horizontally once the block was completed. This process was repeated until the wall was built with the desired dimensions. Besides monuments, rammed earth technique was widely used also for affordable dwellings in response to the large housing demand, as for instance in Alentejo (Southern Portugal), where a considerable vernacular heritage is found [10][11].

Earthen buildings are also well known for their high seismic risk, which results from the high seismic hazard where they are located, the high seismic vulnerability of the structures and the high seismic exposure, as it has been demonstrated by calamities caused by recent earthquakes (e.g. Bam 2003, Pisco 2007, Maule 2010 [12][13]). In general, the seismic vulnerability of rammed earth constructions is due to low mechanical properties of the material, high selfweight and poor connection between structural elements, resulting in in-plane cracking of walls 
and out-of-plane mechanism of bearing walls with collapse of roofs and floors [14][15]. In the past, traditional strengthening techniques, such as steel ties, buttresses or ring beams, were largely used based on empirical knowledges, though they resulted efficient [16].

As a response to mitigate the high seismic vulnerability, the textile reinforced mortar (TRM) strengthening, which is demonstrated to be an efficient solution for masonry buildings $[17][18][19]$, is here proposed for rammed earth dwellings because of its low self-weight, high tensile strength and ductility. The TRM is a composite system where an inorganic matrix has the role to bond the fibers, confer compressive strength and grant geometrical stability, while the mesh provides tensile strength and capacity to distribute the forces through adequate adhesion and friction within the matrix [17][20][21]. Several experimental investigations on the TRM technique for adobe were conducted on structural elements and mock-ups $[21][22][23][24][25][26][27]$. Synthetic meshes were externally applied by means of earthbased mortars and revealed to be an efficient solution for in-plane and out-of-plane loads, thus reducing the seismic risk of adobe houses. Indeed, in most of the cases, the shear strength of the elements and the overall structural ductility was improved; while in other cases, although the model presented evident damage, the TRM prevented the overturning of the walls [28][29][30]. Furthermore, the fact that TRM is an affordable solution is a key aspect considering the low-cost of earthen buildings.

Research on TRM strengthening for rammed earth buildings started recently and the first outcomes show improvement of the overall seismic capacity similar to that obtained in the case of adobe [13][31][32]. Nevertheless, the very few researches conducted so far lack a comprehensive approach of the strengthening system, as the global performance of the reinforcement is the main addressed aspect. In fact, the local behavior, which represents the starting point to predict the response of the strengthened structure, is overlooked. Furthermore, insufficient attention is paid 
to the "compatibility" of the strengthening system, which is required to ensure long-term effectiveness and durability of the interventions [33].

It is evident that the characterization of each TRM component and of their interaction is fundamental to define the local response of the strengthening solution. Similar approach is followed in research of TRM for masonry buildings, where direct tensile tests on coupons show how the mortar improves the initial stiffness of the mesh, while the latter distributes the load when the matrix is cracked. Pull-out tests and single-lap shear tests were carried out to investigate the mortar-mesh interface and substrate-mortar-mesh interaction, respectively. It was found that the performance and type of failure of TRM is affected by the properties of each component and the bonded length of the mesh. Then, an effective bonded length is defined as the minimum length needed to obtain the maximum debonding force neglecting the contribution of the friction $[34][35][36][37][38]$. With regard to the characterization of TRM for rammed earth dwellings, Oliveira at al. [39] conducted first exploratory studies on different earth-based mortars and meshes; among which nylon mesh and glass fiber mesh presented appropriate geometrical properties and were workable for strengthening, while unstabilized earth mortar showed adequate shrinkage and strength properties. Given the above, an experimental program was undertaken, within the framework of the research project SafEarth, and its latest results are presented in this paper. In order to investigate the local response of TRM for rammed earth, firstly, the mechanical properties of each material component were characterized, which included rammed earth, two earth-based mortars and two meshes. Then, the different interaction levels (mesh-mortar and TRM-rammed earth) were investigated by means of direct tensile tests on coupons, pullout tests and single-lap shear tests, while considering different bonded lengths. Hereafter, the experimental campaign is described, then the results are presented and the findings discussed. 


\section{Experimental program and results}

The experimental program was initiated with the characterization of each component of a TRM strengthened system idealized for rammed earth, namely of the substrate (rammed earth), matrix (two earth-based mortars) and reinforcing textile (glass fiber and nylon meshes). Subsequently, the interaction behavior between the components was characterized by means of direct tensile tests on TRM coupons, pull-out tests and single-lap shear tests.

\subsection{Materials}

\subsubsection{Rammed earth}

Manufacturing rammed earth samples required using a representative soil, which was collected from Alentejo, southern Portugal. Subsequently, the soil was characterized by means of geotechnical tests and its suitability for rammed earth construction was evaluated. The characterization of the soil included the determination of the particle size distribution [40], standard Proctor maximum dry density at optimum moisture content [41] and consistency limits [42]. As can be seen from Figure 1, the particle size distribution curve (original soil) does not respect the envelope of soils suitable for rammed earth construction recommended by Houben and Guillaud [1], which intends to ensure proper dry density of rammed earth, thus compressive strength and to avoid shrinkage cracking. According to Table 1, the soil presents high clay content $(29 \%)$ and low sand and gravel contents (21\% and $18 \%$, respectively). These characteristics are not suitable for rammed earth, since such high clay content is expected to result in severe shrinkage cracks during the drying. Furthermore, the Proctor test results summarized in Table 1 evidence that this soil is not able to achieve adequate density after compaction, since the maximum dry density $\left(\rho_{d}\right)$ for an optimum water content $(O W C)$ of $18 \%$ was of about $1.81 \mathrm{~g} / \mathrm{cm}^{3}$. Also, such high value of the OWC anticipates severe drying shrinkage problems. The Atterberg's limits values are presented in Table 1, where the liquid limit $(L L)$ is of about 
$45 \%$ and the plastic limit $(P L)$ of about $24 \%$. The respective clay activity index is of 0.72 , which classifies the clay as inactive, meaning that the composing clay minerals are not expected to undergo significant volume changes when wetted and dried [43].

As a result from the geotechnical characterization, the soil requires correction for casting rammed earth specimens. The correction was conducted by addition of gravel and coarse sand in proportions to fit the new particle size distribution in a Fuller curve. The defined mixture is constituted by $40 \%$ of original soil, $30 \%$ of granitic gravel with size in range of $4.76-9.52 \mathrm{~mm}$ and $30 \%$ of granitic coarse sand with size in range of $0.25-0.85 \mathrm{~mm}$.

Figure 1 shows also that the corrected particle size distribution fits within the envelope recommended by Houben and Guillaud [1], while Table 1 shows that the clay content decreased to $12 \%$, while the sand and gravel contents increased to $34 \%$ and $41 \%$, respectively. Thus, a reduced shrinkage is expected in rammed earth samples. According to the results of the standard Proctor test, the correction of the soil also allowed to increase the maximum dry density to $2.13 \mathrm{~g} / \mathrm{cm}^{3}$ at an optimum water content of $10 \%$ (see Table 1 ).

The mechanical properties (compressive strength and Young's modulus) of the rammed earth elements were evaluated by means of compression tests on three cylindrical specimens, which were manufactured by considering the parameters obtained from the standard Proctor test. The specimens were produced by compacting the moist soil inside a cylindrical metallic mold in 3 layers with $\pm 67 \mathrm{~mm}$ thick and $\pm 100 \mathrm{~mm}$ of diameter, totalizing a height of $\pm 200 \mathrm{~mm}$. The rammer used for manufacturing the cylinders provided a compaction energy of $594 \mathrm{~kJ} / \mathrm{m}^{3}$. To simulate the traditional manual compaction, each layer was compacted through 25 blows controlling the weight and the final thickness.

The specimens were tested after a drying period of 28 days in controlled climatic conditions $\left(\mathrm{T}=20 \pm 2{ }^{\circ} \mathrm{C}\right.$ and $\mathrm{RH}=57.5 \pm 5 \%$ ), which resulted in average bulk density of $2.08 \mathrm{~g} / \mathrm{cm}^{3}(\mathrm{CoV}=$ $3 \%$ ). The compression tests were performed under monotonic displacement control with speed 
$1.5 \mu \mathrm{m} / \mathrm{s}$ to avoid influence of the loading rate on the stiffness of the material. The axial deformations at the middle third section of the specimens were monitored by means of three LVDTs disposed radially, while the load was monitored with a load cell. The results show an average compressive strength $\left(f_{c}\right)$ of about $1.5 \mathrm{MPa}(\mathrm{CoV}=10 \%)$ and average Young's modulus $(E)$, computed by linear fitting in the range $0-30 \% f_{c}$, of about $471 \mathrm{MPa}(\mathrm{CoV}=18 \%)$, while the failure mode of the specimens is illustrated in Figure 2 and is mainly characterized by a wellformed cone on one end.

\subsubsection{Earth-based mortars}

Since the different tests were conducted in different periods, the same soil supplying was not possible; thus two slightly different compositions of earth-based mortars were used in the experimental program, namely EM1 in the pull-out test and EM2 in the direct tensile tests and single lap-shear tests. The EM1 was manufactured with the soil characterized in a previous investigation [44] (“original soil") sieved through a $2 \mathrm{~mm}$ aperture size mesh. This sieved soil was corrected by addition of fine sand in weight ratio of 1:2 (soil : sand) due to its high clay content, which was reduced to $11 \%$. It should be noted that the clay content of earth-based mortars should be limited in order to minimize its water content and thus mitigate possible shrinkage cracking. The water content $(W / S)$ was iteratively defined as $18 \%$ by setting a value of $170 \mathrm{~mm}$ for the flow table test [45] and according to Gomes et al. [46]. The mechanical properties of the mortar EM1 were characterized according to EN 1015-11 [47]. After a drying period of 28 days under constant hygrothermal conditions $\left(\mathrm{T}=20 \pm 2{ }^{\circ} \mathrm{C}\right.$ and $\left.\mathrm{RH}=57.5 \pm 5 \%\right)$, three prismatic samples with dimensions $40 \times 40 \times 160 \mathrm{~mm}^{3}$ were tested under three-point bending loading under monotonic displacement control at speed $1.5 \mu \mathrm{m} / \mathrm{s}$. Then, the remaining parts of the specimens were tested under compression at a constant speed of $25 \mu \mathrm{m} / \mathrm{s}$. These test speeds were defined to achieve failure within a period of 30 s and 90 s of test [47]. The average values obtained were $0.5 \mathrm{MPa}(\mathrm{CoV}=14 \%)$ for flexural strength $\left(f_{b}\right)$ and $1.17 \mathrm{MPa}$ 
$(\mathrm{CoV}=12 \%)$ for compressive strength $\left(f_{c}\right)$. Additionally, the Young's modulus $(E)$ of the mortar was evaluated by means of axial compression tests on three cylindrical specimens with $90 \mathrm{~mm}$ of diameter and $175 \mathrm{~mm}$ of height, casted and dried under the same conditions of the prismatic specimens. The tests were conducted under displacement control at constant speed of $1.5 \mu \mathrm{m} / \mathrm{s}$, while the load was monitored with a load cell and the axial deformations at the middle third section of the specimens were monitored with three LVDTs disposed radially. The Young's modulus $(E)$ was computed by linear fitting of the stress-strain curves in the range 0$30 \%$ of $f_{c}$. The average value obtained was of about $4915 \mathrm{MPa}(\mathrm{CoV}=20 \%)$.

The mortar EM2 was defined after a preliminary characterization of three compositions, where the same soil used to manufacture the rammed earth specimens was sieved to remove the particles larger than $2 \mathrm{~mm}$. Since the sieving process resulted in a clay fraction of about $36 \%$, fine sand was added in three different proportions to achieve the clay percentage fixed at $9 \%$ (EM2.I), 11\% (EM2.II) and 12\% (EM2.III) (see

Table 2). The definition of the W/S and mechanical characterization of each composition followed the same procedures used for mortar EM1. Additionally, the linear shrinkage $\left(S_{L}\right)$ was determined by means of the Alcock's test [48]. The results obtained for each composition are reported in

Table 2. The selected mortar EM2 for TRM strengthening corresponds to composition EM2.I, since it was the only composition with $\mathrm{S}_{\mathrm{L}}$ inferior to $2 \%$, which is the maximum limit recommended in Gomes [49].

The Young's modulus of the mortar EM2 was also evaluated following the same procedure used for mortar EM1 resulting in $1978 \mathrm{MPa}(\mathrm{CoV}=21 \%)$. Figure 3 presents the typical failure mode of the specimens, which is characterized by diagonal fracture.

\subsubsection{Characterization of the meshes}

Oliveira at al. [39] performed a characterization of eight low-cost meshes available locally, which were selected considering their sufficient flexibility to allow its application in TRM strengthening and adequate aperture size $(4-22 \mathrm{~mm})$ to permit satisfactory embedding of the 
mortar and adhesion to the support. Two meshes were then selected from this past study to integrate the experimental program, namely a glass fiber mesh (GM) and a nylon mesh (NM). As illustrated in Figure 4, each mesh presents different weft or geometrical features along the orthogonal orientations, meaning that their physical characterization required assessing both the longitudinal $(\mathrm{X})$ and transversal directions $(\mathrm{Y})$. Table 3 presents the physical properties of the meshes in terms of mesh size, linear density (TEX) [50], grammage (GSM) [51], density $(\rho)$ and average cross section of a single yarn $\left(A_{\text {yarn }}\right)$. Additionally, the price per unit area of each mesh is also included, where the nylon mesh is shown to be $35 \%$ cheaper than glass fiber mesh. The nylon mesh, with respect to the glass fiber mesh, presents larger mesh size, linear density (in both directions) and cross-section area, while the grammage and density are lower. According to CNR-DT $200 \mathrm{R} 1$ [52], both GM and NM meshes meet the grammage requirement for fabrics integrating composites materials, whose value should be lower than $600 \mathrm{~g} / \mathrm{m}^{2}$.

The tensile behavior of the dry meshes was evaluated according to the procedure prescribed by ASTM D6637 [53] and RILEM TC-250 CSM [54]. Five specimens were prepared per mesh type with width of about $50 \mathrm{~mm}$, but with free length depending on the mesh type, namely $300 \mathrm{~mm}$ for GM and $200 \mathrm{~mm}$ for NM. For each type of mesh, the direction along which they show higher tensile capacity, as found in Oliveira at al. [39], was considered when preparing the specimens. Steel plates were fixed at the extremities of each specimen, in an additional bonded length of $50 \mathrm{~mm}$, using an epoxy compound. The tests were conducted under displacement control; though different testing speeds were adopted according to the mesh type, namely $10 \mu \mathrm{m} / \mathrm{s}$ for GM and $100 \mu \mathrm{m} / \mathrm{s}$ for NM. It should be noted that the shorter free length and higher testing speed of NM mesh were adopted due to its considerable deformability. The axial deformation between clamps was monitored using a single LVDT, while a load cell was used to monitor the load as shown in

Figure 5.

The results of the tensile tests are presented in Figure 6 in terms of linear force, defined as load per linear width of the specimen, against axial strain curves. The graphs show that the GM is characterized by an elastic response up to the maximum force, then the resistance drops when 
fibers and yarns break until the complete failure (Figure 6a). On the other hand, the NM behavior is predominantly non-linear up to failure, which corresponds to the maximum linear force (Figure 6b). Table 4 summarizes the respective mechanical properties and compares them with those of meshes used in commercial TRM strengthening systems, where $F_{w, p}$ is the maximum linear force, $f_{t}$ is the average tensile strength of a single yarn and $\varepsilon_{p e a k}$ is the peak axial strain. Additionally, the average Young's modulus of a single yarn was computed by linear fitting of the tensile stress-strain curve in the range $0-30 \% f_{t}$. When comparing GM and NM meshes, the nylon mesh presented much lower resistance than the glass fiber mesh (around $17 \%$ of GM); while the latter is characterized by higher deformability; indeed the elastic modulus of NM resulted around $1.1 \%$ of GM, while the peak axial strain of GM is around $6.2 \%$ of NM.

When comparing the GM and NM meshes with those from TRM strengthening systems for masonry, such as basalt, alkali-resistant fiberglass or stainless steel, the latter are stronger and significantly stiffer, thus the compatibility of deformations between these meshes and rammed earth is not expected to be possible. Furthermore, the high tensile capacity of these meshes is unlikely to be suitably exploited when applied on earthen supports.

\subsection{Characterization of the tensile behavior of TRM coupons}

The interaction between earth mortar and mesh was investigated through direct tensile tests performed on TRM coupons. For both GM and NM, five samples with width of $50 \mathrm{~mm}$ (corresponding to 3 nylon yarns and 5 glass fiber yarns) and free length of $300 \mathrm{~mm}$ length were

embedded in $10 \mathrm{~mm}$ thick EM2 mortar layer. Each specimen was labeled as TC\#type of mesh\#number of specimen (e.g. TCNM2). After manufacturing, the specimens were dried during a period of 28 days under laboratory conditions. Then, steel plates were fixed with epoxy compound to the additional mesh length at each of the extremities of the specimens for a bonded length of $50 \mathrm{~mm}$. The tests were conducted under displacement control with speed 
depending on the type of mesh being tested. In the GM case, the speed test was $1 \mu \mathrm{m} / \mathrm{s}$ until achieving a displacement of $3 \mathrm{~mm}$, after which it was increased to $10 \mu \mathrm{m} / \mathrm{s}$ up to failure. In the NM case, the speed was $10 \mu \mathrm{m} / \mathrm{s}$ up to $6 \mathrm{~mm}$ of displacement and then it was increased to $100 \mu \mathrm{m} / \mathrm{s}$ up to failure. The axial deformations were recorded by a LVT fixed between the clamps, while the tensile load was monitored with a load cell. Figure 7 shows the direct tensile coupon test scheme.

The results of the tensile tests are presented in terms of linear force-axial strain curves and failure mode in Figure 8 and

Figure 9 for TCGM and TCNM, respectively. Before analyzing the results in detail, it should be noted that the typical 3-stages behavior of TRM coupons [17] [55] was observed in all cases, namely: the initial stiffness showing the uncracked behavior of the mortar fully bonded to the mesh (stage I); cracking development (stage II); fully cracked behavior (stage III). In the TCGM case, specimens TCGM1 and TCGM4 are considered as outliers (dashed line) due to defects of the embedded mesh and their curves are considered only in the analysis of the uncracked and cracking development stages, while the average maximum linear force is 14.82 $\mathrm{kN} / \mathrm{m}$ (about $750 \mathrm{~N})(\mathrm{CoV}=21 \%)$, see Figure 8a. Furthermore, the failure mode was characterized by the progressive detachment of the mortar from the mesh followed by the tensile failure of the mesh itself (Figure 8b).

As for the TCNM case, only the specimen TMN1 is considered as an outlier (dashed line), thus it is considered only in the analysis of stage I and stage II, while the average maximum linear force resulted equal to $3.14 \mathrm{kN} / \mathrm{m}$ (about $160 \mathrm{~N})(\mathrm{CoV}=15 \%)$. In this case, the cracking development was characterized by a widespread and more uniform distribution of cracks than that of TCGM, due to the lower stiffness and higher deformation capacity of the NM mesh ( Figure 9). Furthermore, the larger aperture size of NM promoted a better embedding of the mesh and prevented the detachment of the mortar during the stage III.

The influence of the mesh stiffness is evident when the cracking development stage of TCGM and TCNM is compared. Indeed, the stage II of the stiffer TCGM started earlier and was fully 
evolved within a short strain range (up to about $0.003 \mathrm{~mm} / \mathrm{mm}$ ), while in case of the more deformable TCNM, cracks developed within a larger strain range (up to about $0.15 \mathrm{~mm} / \mathrm{mm}$ ), as shown in Figure 10a and Figure 10b, respectively.

Figure 11 highlights the changes in behavior introduced by the TRM coupons with respect to the behavior of the dry meshes. In both cases, a significant increase of the stiffness is observed at the initial stage, due to the contribution of the mortar. As this contribution is dissipated by cracking development, the behavior tends to approximate to that of the dry mesh. Furthermore, the average maximum linear force achieved in TCNM $(3.14 \mathrm{kN} / \mathrm{m})$ is similar to the one obtained in TNM $(3.18 \mathrm{kN} / \mathrm{m})$, while the strength of TCGM $(14.82 \mathrm{kN} / \mathrm{m})$ is lower than the one of TGM $(18.42 \mathrm{kN} / \mathrm{m})$. This suggests that the friction between earth mortar and mesh causes damage to glass fibers.

\subsection{Characterization of the matrix-fiber bond behavior}

The interaction between the mortar and the embedded mesh was further investigated by means of pull-out tests, where different bonded lengths were tested depending on the mesh type. In the GM case, the bonded lengths considered were $30 \mathrm{~mm}, 50 \mathrm{~mm}, 90 \mathrm{~mm}$ and $150 \mathrm{~mm}$, while those adopted for NM were $15 \mathrm{~mm}, 20 \mathrm{~mm}, 30 \mathrm{~mm}, 50 \mathrm{~mm}$ and $70 \mathrm{~mm}$. The pull-out specimens consisted of EM1 mortar cylinders with diameter of $\pm 150 \mathrm{~mm}$ and height corresponding to the bonded length. Five specimens were casted per bonded length, ensuring the correct filling of the mold and perfect alignment of a single mesh band with $50 \mathrm{~mm}$ width, while the unbonded part of the mesh was kept vertically to avoid any damage due to bending. The molds were previously drilled to promote the drying of the mortar and oiled before casting to facilitate the removal of specimen after drying. Each specimen was labelled according to the nomenclature PO\#type of mesh\#bonded length\#number of specimen (e.g. POGM1). The drying of the speci-

mens took place for a period of 28 days under constant hygrothermal conditions $\left(T=20 \pm 2{ }^{\circ} \mathrm{C}\right.$ and $\mathrm{RH}=60 \pm 5 \%$ ), after which they were subjected to displacement controlled pull-out tests. 
Different testing speeds were used for the POGM and PONM specimens, respectively, $10 \mu \mathrm{m} / \mathrm{s}$ and $50 \mu \mathrm{m} / \mathrm{s}$. The displacements of the mesh were recorded by means of one LVDT set at the free end and two LVDTs set at the loaded end close to the mortar surface, while the load was recorded by a load cell (Figure 12a).

The three types of failure modes observed during the tests are illustrated in Figure 12b, namely: tensile failure at the unbonded part of the mesh (FM1), tensile failure in an embedded section of mesh (FM2) and mesh slipping within the mortar (FM3). These modes are latter discussed with respect to the different types of specimens in terms of mesh and bonded length adopted. Figure 13 presents the response curves in terms of linear force, displacement at the loaded end and displacement at the free end, while the results of the POGM specimens are reported in Table 5 in terms of bonded length $\left(L_{b}\right)$, maximum linear force $\left(F_{w, p}\right)$ and failure mode $(F M)$. In general, the response observed is initially elastic, followed by a non-linear behavior until brittle failure is reached, as found in TRM composite systems used in masonry buildings $[56][57][58][59][60][61]$. During the elastic stage, the load is transferred from the yarns to the matrix by adhesion until the bond strength is achieved, subsequently micro cracks are developed on the interface mortar-mesh and the non-linear response begins. In the non-linear stage, both mechanisms of adhesion and friction coexist until the bond strength is attained in the section corresponding to the free end. Then, sliding of the mesh onsets at this section and friction controls the load transfer from the mesh to the matrix.

The pull-out tests results of the PONM specimens are presented in Table 6, while Figure 14a presents the respective response curves in terms of linear force-displacement at the loaded end. It should be noted that the response of these specimens is not representative of a typical fiber-matrix behavior, since the bonded length does not affect the maximum values of the linear force, which is similar to the tensile capacity of the dry mesh (equal to $3.2 \mathrm{kN} / \mathrm{m}$ ), see

Figure 14b. Furthermore, failure occurred due to rupture of the mesh at an unbonded section (FM1) and no sliding at the free end was observed in all cases. Hence, for PONM specimens 
the bond was granted by mechanical anchoring promoted by the transversal yarns, which are welded to the longitudinal ones. In fact, a single transversal yarn embedded in the mortar was found to be sufficient to achieve the full tensile capacity of the mesh, as is the case of the specimens with $15 \mathrm{~mm}$ and $20 \mathrm{~mm}$ bonded length.

\subsection{Characterization of the substrate-matrix-fiber bond behavior}

Single-lap shear tests were conducted according to [54] in order to investigate the full interaction between rammed earth, mortar and mesh under shear loads. To this purpose, specimens manufactured with GM and NM meshes and different bonded lengths were considered, while fixing the width of the TRM in $80 \mathrm{~mm}$. The support used to prepare the specimens consisted of rammed earth blocks with dimensions of $150 \times 100 \times 200 \mathrm{~mm}^{3}$. The blocks were compacted in three layers using the corrected soil mixture referred to in Section 2.1.1, while considering the maximum dry density and optimum water content obtained from the Proctor test. The drying of the blocks occurred for a period of 28 days, after which the TRM strengthening was applied on one of the largest surfaces. First, a layer of earth mortar EM2 with $5 \mathrm{~mm}$ thickness, $80 \mathrm{~mm}$ width (corresponding to 5 nylon yarns and 8 glass fiber yarns) and length equal to the bonded length was applied after scraping with a steel brush and wetting (spraying) the surface of the rammed earth block to promote adherence of the mortar and prevent early water reduction in the mortar. Then, a single mesh band with $80 \mathrm{~mm}$ width was placed on the mortar parallel to the surface of the support and covered with a second layer of mortar with $5 \mathrm{~mm}$ thick. In the NM case, just a single bonded length of $30 \mathrm{~mm}$ was considered since no sliding was expected, as observed in the pull-out tests, while for GM four different bonded lengths were considered, namely $30 \mathrm{~mm}, 60 \mathrm{~mm}, 90 \mathrm{~mm}$ and $120 \mathrm{~mm}$. Five specimens were prepared for each type of mesh and bonded length. Each specimen was labelled according to the nomenclature SL\#type of mesh\#bonded length\#number of specimen (e.g. SLNM3). The single-lap shear tests were conducted after drying the TRM mortar for 28 days in laboratory conditions according to the test setup illustrated in

Figure 15a. Steel plates were bonded to the loaded end extremity with an epoxy compound to allow the gripping in the testing machine, while the rammed earth block was fixed to the steel frame. The test was conducted under monotonic displacement control with speed $10 \mu \mathrm{m} / \mathrm{s}$, both for SLGM and SLNM specimens. The displacement of the mesh at the loaded end was 
monitored by means of two LVDTs set in the mesh immediately after the mortar, while one LVDT was used to monitor the displacements at the free end. The applied force was recorded by means of a load cell.

Regarding the results of the single-lap shear tests, only three failure modes of those typically reported in TRM strengthened masonry [17][38][55] were observed in this work (see

Figure 15b), namely: debonding at the support-mortar interface (FM1); sliding of the textile with detachment of the top mortar layer (FM2); mixed failure at the support-mortar interface and detachment of the top mortar layer (FM3). Table 7 presents the results of the single-lap shear tests on the SLGM specimens in terms of maximum linear force $\left(F_{w, p}\right)$ and failure mode $(F M)$, while

Figure 16 presents the respective response curves in terms of linear force, displacement at the loaded end and displacement at the free end. Unfortunately, the loaded end displacements of some specimens (SLGM30_1, SLGM30_2, SLGM60_1, SLGM60_2, SLGM90_4 and SLGM_90_5) were not properly measured.

The response is elastic followed by a non-linear behavior and brittle failure. During the elastic stage, the load transfer is governed by adhesion, namely from the yarn to the matrix and then from the matrix to the support, until the maximum interfacial shear stress is achieved. Afterwards, micro-cracks develop either at the mortar-mesh or rammed earth-mortar interfaces. At this stage, the non-linear response begins, meaning that the adhesion and friction mechanisms coexist. The destruction of the adhesion between mesh and mortar at the free end results in the onset of the sliding of the mesh in this section, following which, friction is the mechanism allowing to transfer load from the mesh to the matrix, and from there to the support. Failure is achieved when either the cohesion is destroyed in the rammed earth-mortar interface $(F M 1)$ or when the interfacial shear stresses at the mortar-mesh interface reach the strength of the mortar (FM2).

The results of the SLNM specimens are presented in Figure 17 and Table 8. Despite the singlelap shear tests provide displacements at the free end similar to those ones obtained for SLGM 
specimens at loaded end, the characteristic curve is different. After the elastic response, the non-linear branch does not present the same plateau as in case of glass fiber mesh, although the ultimate displacement achieved in the loaded end is higher in case of nylon mesh. This could explain a local deformation of the nylon mesh, but still the failure mode was ascribed to the interface mortar-rammed earth $(F M 1)$ in all cases.

\section{Discussion of the results}

In the following sections, the results of experimental campaign of pull-out tests and single-lap shear tests are reported and discussed.

\subsection{Pull-out tests}

A descriptive statistical analysis of the pull-out results from the POGM specimens was performed considering the bonded length $\left(L_{b}\right)$ and the maximum linear force $\left(F_{w, p}\right)$ (Figure 18a), linear force at the sliding onset $\left(F_{w, s}\right)$ (Figure 18b), ultimate displacement at the loaded end $\left(D_{L E, u}\right)$ (Figure 18c), ultimate displacement at the free end $\left(D_{F E, u}\right)$ (Figure 18d), displacement at the loaded end for the maximum linear force $\left(D_{L E, F w, M a x}\right)$ (Figure 18e) and linear force at the end of the elastic phase $\left(F_{E l}\right)$ (Figure 18f). It should be noted that the ultimate displacements were defined considering the displacement at failure or when the linear force dropped $80 \%$ of $F_{w, p}$. The boxplots represent the median, the 25 th and 75 th percentiles, while the whiskers are the maximum and the minimum of the data set.

Figure 18a shows that the bonded length $\left(L_{b}\right)$ and the maximum linear force $\left(F_{w, p}\right)$ seem to follow a bilinear relationship. For the bonded length of $30 \mathrm{~mm}$, failure occurred due to sliding of the mesh inside the mortar (FM3), thus without full exploitation of its tensile capacity. For larger bonded lengths, failure occurred due to rupture of an embedded mesh section (FM2), but again full exploitation of the tensile strength of the mesh was not achieved in any case. Furthermore, the maximum linear force is shown to increase with the bonded length up to $90 \mathrm{~mm}$, 
after which the maximum linear force seems to attain a constant value. This behavior indicates that the minimum bonded length to fully develop the anchoring of the mesh is of about $90 \mathrm{~mm}$. It should be noted that the glass fiber mesh yarns are made of bundles of fibers and that only the external ones interact directly with the mortar and then transfer the load to the core fibers [60], while the core of the yarn can slip more easily. This mechanism may lead to telescopic behavior of the yarns [54] in which successive breaking down of filaments from the sleeve to the core prevents the full exploitation of the mesh tensile capacity.

Figure $18 \mathrm{~b}$ shows that the linear force to onset sliding at the free end seems to increase linearly with the bonded length, while comprising values substantially lower than that of the maximum linear force. Such difference could suggest that sliding also activates an improved bond configuration due to interlocking of the yarns inside the mortar. Nevertheless, the friction generated at each yarn is not expected to assume an even distribution along the bonded length mainly due to different damage levels of the mortar surrounding the yarns. Uneven stress levels are also expected to lead to premature failure of the mesh. Figure $18 \mathrm{c}$ suggests that FM2 is correlated to the slipping level, since the ultimate displacement at the loaded end becomes apparently constant (values between $2 \mathrm{~mm}$ and $4 \mathrm{~mm}$ ) for bonded lengths larger than $30 \mathrm{~mm}$. Hence, the wearing caused by such level of displacement is probably the cause of failure. The fact is that the ultimate displacement at the loaded end and the displacement at the loaded end for the peak linear force assume identical values for bonded lengths larger than $30 \mathrm{~mm}$ (see Figure 18d). Regarding the ultimate displacement at the free end, Figure 18d seems to show that the larger is the bonded length, the lower is the displacement, meaning that larger bonded lengths provide higher restraint to sliding of the mesh.

Finally, Figure 18f allows to identify two groups of bonded lengths (30-50 mm and 90-150 $\mathrm{mm}$ ) in which the linear force at the end of the elastic phase is comparable. The group with shorter bonded lengths shows considerably lower values than those of the group with higher 
bonded lengths, indicating that for a bonded length shorter than $90 \mathrm{~mm}$ seems not to be possible to fully develop the elastic load capacity of the mesh-mortar interface.

\subsection{Single-lap shear tests}

A descriptive statistical analysis of the results from the single-lap shear tests on the SLGM specimens was performed considering the bonded length $\left(L_{b}\right)$ and maximum linear force $\left(F_{w, p}\right)$ (Figure 19a), linear force to onset displacement at the free end $\left(F_{w, s}\right)$ (Figure 19b), displacement at the loaded end for the maximum linear force $\left(D_{L E, F w, p}\right)$ (Figure 19c) and ultimate total sliding $\left(S_{u}\right)$ (Figure 19d), calculated as the difference between the displacement at the free end and displacement at the loaded end for $80 \%$ of peak linear force (decreasing branch). The boxplots represent the median, the 25 th and 75 th percentiles, while the whiskers are the maximum and the minimum of the data set. Figure 19a evidences a likely linear correlation between the bonded length $\left(L_{b}\right)$ and maximum linear force $\left(F_{w, p}\right)$, while Figure $19 \mathrm{~b}$ seems to show a bilinear relationship between the bonded length $\left(L_{b}\right)$ and the linear force to onset sliding at the free end $\left(F_{w, s}\right)$. Indeed, the linear force required to onset the displacement at the free end increases up to $90 \mathrm{~mm}$ of bonded length and then remains constant. Afterwards, the bond is governed by friction between mesh and mortar, which further increases the linear force until failure at the interface between mesh and mortar (FM2 and FM3). This type of failure could be promoted by the fact that sliding of the mesh damages the matrix surrounding the yarns. The contribution of friction is further evidenced by the increasing of maximum linear force with the increasing of both displacement at loaded end at peak load $\left(D_{L E, F w, p}\right)$ (Figure 19c) and sliding at failure $\left(S_{u}\right)$ (Figure 19d).

Since the series SLGM120 presented a mixed failure mode $(F M 3)$ and failure at the interface mortar-mesh (FM2), a further statistical analysis was conducted selecting the data according to the failure modes. The results are reported in Table 9 and discussed as percent difference of maximum linear force $\left(F^{\prime}{ }_{w, p}\right)$, linear force to onset displacement at the free end $\left(F^{\prime}{ }_{w, S}\right)$, 
displacement at the loaded end for the maximum linear force $\left(D^{\prime}{ }_{L E, F w, p}\right)$, ultimate sliding $\left(S_{u}^{\prime}\right)$ and their relative coefficient of variance. No influence of type of failure on maximum linear force $\left(F^{\prime}{ }_{w, p}\right)$ is observed, since the difference of coefficient of variation is not substantial. A correlation between the mixed failure mode and the linear force to onset the displacement $\left(F^{\prime}{ }_{w, s}\right)$ was observed, as the average value decreased $14 \%$ and the scattering is reduced. In this case, the linear force to the displacement onset is in the range of values of the series SLG90, which was characterized by FM2. This suggests that after the cracking and detachment of the mortar, the bonded length reduced from $120 \mathrm{~mm}$ to $90 \mathrm{~mm}$, responding as the case of SLG90. Also, no correlation is observed considering the displacement at loaded end at peak load $\left(D^{\prime}{ }_{L E, F w, p}\right)$ and the ultimate sliding $\left(S^{\prime}{ }_{u}\right)$.

The responses obtained from the direct tensile (average value), pull-out and single-lap shear tests for GM are compared together in Figure 20 in terms of maximum linear force and linear force to onset sliding at the free end. The maximum linear force achieved in the single-lap shear tests is in general lower than the maximum linear force achieved in the pull-out tests. Furthermore, the predominant failure mode observed in the single-lap shear tests was detachment of the mortar at the interface with fabric or with the support, while no damage was reported in the mesh. This behavior indicates that the interface between matrix and textile or rammed earth and matrix represents the weakness of the GM TRM system.

\section{Conclusions}

This paper characterizes experimentally the behavior of a proposed TRM-based compatible strengthening solution for rammed earth constructions. In particular, the three components (rammed earth, earth mortar and textile mesh) and their interaction were investigated through an experimental program. To the knowledge of the authors, these are the first experimental results published on the topic. 
Two earth-based mortars were proposed to integrate the TRM strengthening system and their mechanical properties were characterized presenting sufficient compressive and flexural strength for TRM strengthening.

The glass fiber and nylon meshes presented aperture size and mass per unit area appropriate for their use in composite materials, but their behavior was found to be substantially different. The glass fiber mesh showed a considerably higher stiffness and tensile strength than those of the nylon mesh. In this last case, the low stiffness may represent an issue, since large deformations are required to fully mobilize the tensile capacity of the mesh. In spite of their different behavior, both meshes are deemed to represent interesting solutions to enhance the structural capacity and ductility of rammed earth walls.

The direct tensile tests on TRM coupons showed that the initial stiffness of the composite is higher than the stiffness of the mesh alone. The influence of the different geometrical and mechanical characteristics of the meshes in the composite is found when the cracking stage (stage II) and the type of failure are compared. In the case of the nylon mesh, the cracks are even distributed and the stage II is fully evolved in a longer range of strain. While, in case of glass fiber mesh, detachment of the mortar occurs after stage II.

The pull-out tests revealed distinct responses depending on the mesh type and embedded length. In the case of the glass fiber mesh, the tensile rupture of the mesh within the embedded portion was the failure mode observed for the bonded lengths of $50 \mathrm{~mm}, 90 \mathrm{~mm}$ and $150 \mathrm{~mm}$, while sliding failure was observed for the bonded length of $30 \mathrm{~mm}$. The maximum linear force was shown to increase with the bonded length up to $90 \mathrm{~mm}$ and apparently remained constant after this value, thus it represents the minimum bonded length to fully develop the anchoring of the mesh. Furthermore, it was found that full exploitation of the tensile strength of the mesh was not possible probably due to damage resulting from wearing friction inside the mortar. The sliding onset took place during the nonlinear part of the pre-peak curve, meaning that the sliding 
of the yarns activates frictional bond mechanisms. The ultimate displacement recorded at the free end was found to decrease with the bonded length, suggesting that larger bonded lengths offer higher restraint to the mesh.

In the case of the nylon mesh, the maximum linear force values achieved in the pull-out tests was similar to the maximum linear force of the mesh, while failure occurred always at an unbonded section of the mesh. Thus, the bond of this mesh is ensured by the transversal yarns which, being welded to the longitudinal ones, promote its mechanical anchoring.

Regarding the single-lap shear tests, the glass fiber mesh specimens exhibited a linear correlation between bonded length and maximum linear force. It was observed that the progression of sliding induces higher friction bond, which is able to increase further the linear force of the TRM. For the mixed failure mode (FM3) in bonded length of $120 \mathrm{~mm}$, the linear force to onset the displacement in the free end was similar to the one obtained in bonded length of $90 \mathrm{~mm}$; hence, the bonded length was reduced after the detachment of the initial length of mortar.

In case of nylon mesh, since a perfect anchoring between mortar and mesh was found in the pull-out tests and the failure at the interface rammed earth-mortar was observed in all the samples of single lap-shear tests, this interface is assumed to be the weakness of TRM system when using nylon mesh.

By comparing results of the entire experimental campaign for glass fiber mesh, the maximum linear force achieved in the pull-out tests is higher than one obtained in single-lap shear tests; though the tensile capacity of the mesh is never attained. Furthermore, the fact that the failure mode observed in single-lap shear tests is mainly at the interface between mortar and mesh indicates this interface as the weakness of the proposed TRM solution using glass fiber mesh. Further analytical investigation is being conducted to fully describe the local response of the TRM. Moreover, diagonal compression tests on plain and strengthened rammed earth wallets 
will be carried out in order to provide additional data on the effectiveness of the strengthening system.

\section{Acknowledgments}

This work was partly financed by FEDER funds through the Operational Programme Competitiveness Factors (COMPETE 2020) and by national funds through the Foundation for Science and Technology (FCT) within the scope of project SafEarth - PTDC/ECM-EST/2777/2014 (POCI-01-0145-FEDER-016737). The support from grants SFRH/BD/131006/2017 and SFRH/BPD/97082/2013 is also acknowledged. Acknowledgments are addressed to master students Cristina Barroso, Aidarbek Stamov and Reza Talakoobi.

\section{References}

[1] Houben H., Guillaud H. (2008) Earth construction: a comprehensive guide. London, Intermediate Technology Publication.

[2] Silva R.A., Oliveira D.V., Miranda T., Cristelo N., Escobar M.C., Soares E. (2013) Rammed earth construction with granitic residual soils: The case study of northern Portugal. Construction and Building Materials, 47, 181-191.

[3] Yamin L.E., Phillips C.A., Reyes J.C., Ruiz D.M. (2004) Seismic behavior and rehabilitation alternatives for adobe and rammed earth buildings. In proc. of $13^{\text {th }}$ World Conference on Earthquake Engineering Conference, Vancouver.

[4] Minke G. (2006) Building with earth, design and technology of a sustainable architecture. Basel- Berlin-Boston, Birkhäuser Architecture.

[5] Pollock S. (1999) Ancient mesopotamia. Cambridge, Cambridge University Press.

[6] Pacheco-Torgal F., Jalali S. (2012) Earth construction: Lessons from the past for future eco-efficient construction. Construction and Building Materials, 29, 512-519. 
[7] Jaquim P.A., Augarde C.E., Gerrard C.M. (2008) A chronological description of the spatial development of rammed earth techniques. International Journal of Architectural Heritage, 2, 377-400.

[8] Jaquin P.A. (2008) Analysis of historic rammed earth construction. PhD thesis, Durham University, United Kingdom.

[9] Fernandes M. (2013) A Taipa no mundo. (C.d. Porto, Ed.) DigitAR, 1, 14-21.

[10] Silva R.A., Mendes N., Oliveira D.V., Romanazzi A., Domínguez-Martínez O., Miranda, T. (2018) Evaluating the seismic behaviour of rammed earth buildings from Portugal: from simple tools to advanced approaches. Engineering Structures, 157, 144-156.

[11] Correia M. (2007) Rammed earth in Alentejo. Lisbon, Argumentum.

[12] Bui T.T., Bui Q.B., Limam A., Maximilien S. (2014) Failure of rammed earth walls: From observations to quantifications. Construction and Building Materials, 51, 295-302.

[13] Liu K., Wang M., Wang, Y. (2015) Seismic retrofitting of rural rammed earth buildings using eternally bonded fibers. Construction and Building Materials, 100, 91-101.

[14] Lourenço P.B., Torrealva D., Cancino C., Wong K., Karanikoloudis G. and Ciocci, M.P. (2017) Innovative traditional technologies for rehabilitation and protection of earthen structures: the Getty Conservation Institute seismic retrofitting project. In proc. of PROHITEC $173^{\text {rd }}$ International Conference on Protection of Historical Constructions, Lisbon.

[15] Costa A.A., Varum H., Rodrigues H., Vasconcelos G. (2015) Seismic behaviour analysis and retrofitting of a row building. In Correia M., Lourenço P.B., Varum H., Seismic Retrofitting: Learning from vernacular architecture. London, Taylor and Francis Group.

[16] Correia M., Carlos G. (2015) Local seismic culture in Portugal. Lisbon, Argumentum.

[17] De Felice G., De Santis S., Garmendia L., Ghiassi B., Larringa P., Lourenço P.B., Oliveira D.V., Paolacci F., Papanicolaou C.G. (2014) Mortar-based systems for externally bonded strengthening of masonry. Materials and Structures, 47, 2021-2037. 
[18] Ghiassi B., Marcari G., Oliveira D.V., Lourenço P.B. (2012) Numerical analysis of bond behavior between masonry bricks and composite materials. Engineering Structures, 43, 210- 220.

[19] Valluzzi M.R., Modena C., De Felice G. (2014) Current practice and open issues in strengthening historical buildings with composites. Materials and Structures, 47, 19711985.

[20] Righetti L., Edmondson V., Corradi M., Borri A. (2016) Fiberglass grids as sustainable reinforcement of historic masonry. Materials, 9, 1-17.

[21] Blondet M., Torrealva D., Garcia G., Ginocchio F., Madueño I. (2005) Using industrial materials for the construction of safe adobe houses in seismic areas. In proc. of Earthbuild 2005 International Conference, Sydney.

[22] Noguez R., Navarro S. (2005) Reparación de muros de adobe con el uso de mallas sintéticas. In proc. of International Conference SismoAdobe 2005: architecture, construction and conservation of earthen buildings in seismic areas, Lima.

[23] Yamin L., Phillips C., Reyes J., Rivero S., Ruiz D. (2007) Estudios de vulnerabilidad sísmica, rehabilitación y refuerzo de casas en adobe y tapia pisada. Apuntes: Revista de estudios sobre património - Journal of Cultural Heritage Studies, 20, 286-303.

[24] Zavala C., Igarashi L. (2005) Propuesta de Reforzamiento para Muros de Adobe. In proc. of International Conference SismoAdobe 2005: architecture, construction and conservation of earthen buildings in seismic areas, Lima.

[25] Vargas J., Blondet M., Ginocchio F., García G. (2005) 35 Años de investigaciones en sismo adobe: la tierra armada, International Conference SismoAdobe 2005: architecture, construction and conservation of earthen buildings in seismic areas, Lima. 
[26] Blondet M., Torrealva D., Vargas J., Velasquez J., Tarque N. (2006). Seismic Reinforcement of Adobe Houses Using External Polymer Mesh. In proc. of First European Conference on Earthquake Engineering and Seismology, Geneva.

[27] Michiels T.L.G. (2014) Seismic retrofitting techniques for historic adobe buildings. International Journal of Architectural Heritage, 9, 1059-1068.

[28] Noguez R., Navarro S. (2005) Reparación de muros de adobe com el uso de mallas sintéticas. In proc. of International Conference SismoAdobe 2005: architecture, construction and conservation of earthen buildings in seismic areas, Lima.

[29] Torrealva D. (2016). Static and dynamic testing for validating the polymer grid as external reinforcement in earthen buildings. In proc. of Brick and Block Masonry: Proceedings of the 16th International Brick and Block Masonry Conference, Padova.

[30] Figueiredo A., Varum H., Costa A., Silveira D., Oliveira C. (2013) Seismic retrofitting solution of an adobe masonry wall. Materials and Structures, 46, 203-219.

[31] Wang Y., Wang M., Liu K., Pan W., Yang X. (2017) Shaking table tests on seismic retrofitting of rammed earth structures. Bulletin of Earthquake Engineering, 3, 1037-155.

[32] Fagone M., Loccarini F., Ranocchiai G. (2017) Strength evaluation of jute fabric for the reinforcement of rammed earth structures. Composites Part B: Engineering, 133, 1-13.

[33] Van Balen K., Papayianni I., Van Hees R., Binda L., Waldum A. (2005) Introduction to requirements for and functions and properties of repair mortars. RILEM TC 167-COM: 'Characterisation of Old Mortars with Respect to their Repair'. Materials and Structures, $38,781-785$.

[34] D’Ambrisi A., Feo L., Focacci F. (2013) Experimental analysis of bond between PBOFRCM strengthening materials and concrete. Composites: Part B, 44, 524-532. 
[35] D’Antino T., Carloni C., Sneed L.H., Pellegrino C. (2014) Matrix-fiber bond behaviour in PBO FRCM composites: a fracture mechanics approach. Engineering Fracture Mechanics, 117, 94-111.

[36] Carozzi F.G., Colombi P., Fava G., Poggi C. (2016) A cohesive interface crack model for the matrix-textile debonding in FRCM composites. Composite Structures, 143, 230241.

[37] D’Antino T., Colombi P., Carloni C., Sneed L.H. (2018) Estimation of a matrix-fiber interface cohesive material law in FRCM-concrete joints. Composite Structures, 193, 103-112.

[38] Focacci F., D’Antino T., Carloni C., Sneed L.H., Pellegrino C. (2017) An indirect method to calibrate the interfacial cohesive material law for FRCM-concrete joints. Materials and Design, 128, 206-217.

[39] Oliveira D.V., Silva R.A., Barroso C., Lourenço P.B. (2018) Characterization of a compatible low cost strengthening solution based on the TRM Technique for Rammed Earth. Key Engineering Materials, 747, 150-157.

[40] LNEC E196 (1966) Análise granulomatrica. Laboratorio Nacional de Engenharia Civil, Lisboa.

[41] LNEC E197 (1966) Solos. Ensaio de compactação. Laboratiorio Nacional de Engenharia Civil, Lisboa.

[42] NP 143 (1969) Solos. Determinação dos limites de consistencia. Norma Portuguesa.

[43] Skempton A.W. (1953) The colloidal activity of clays. In proc. of $3^{\text {rd }}$ International Conference on Soil Mechanics and Foundation Engineering, Zurich.

[44] Silva R.A., Oliveira D.V., Schueremans L., Miranda T., Machado J., (2016) Effectiveness of the repair of unstabilised rammed earth with injection of mud grouts. Construction and Building Materials, 127, 861-71. 
[45] BS EN 1015 (1999) Methods of test for mortar for masonry. Part 3: determination of consistence of fresh mortar (by flow table).

[46] Gomes M.I., Faria P., Gonçalves T.D. (2013) The compatibility of earth-based repair mortars with rammed earth substrates. In proc. of $3^{\text {rd }}$ Historic Mortars Conference, Glasgow.

[47] BS EN 1015 (1999) Methods of test for mortar for masonry. Part:11 determination of flexural and compressive strength of hardened mortar.

[48] Walker P. (2001) The Australian earth building handbook. Sydney, Standards Australia International.

[49] Gomes M.I. (2013) Conservation of rammed earth construction: repairing mortars. PhD thesis, Universidade Nova de Lisboa, Lisbon.

[50] Vasconcelos R. M. (1993). Contribuição à aplicação de técnicas de inteligência artificial na tecnologia da fiação. PhD thesis, Universidade do Minho, Guimarães.

[51] ISO 3374 (2000) Reinforcement products. Mats and fabrics. Determination of mass per unit area.

[52] CNR-DT 200 R1 (2013) Guide for the design and construction of externally bonded FRP systems for strengthening existing structures. Materials, RC and PC structures, masonry structures.

[53] ASTM D6637 (2015) Standard test method for determining tensile properties of geogrids by the single or multi-rib tensile method.

[54] De Felice G., Aiello M.A., Caggegi C., Ceroni F., De Santis S., Garbin E., Gattesco N., Hojdys L., Krajewski P., Kwiecień A., Leone M., Lignola G.P., Mazzotti C., Oliveira D., Papanicolaou C., Poggi C., Triantafillou T., Valluzzi M.R., Viskovic A. (2018) Recommendation of RILEM Technical Committee 250-CSM: Test method for 
Textile Reinforced Mortar to substrate bond characterization . Materials and Structures, 51,95 .

[55] Ascione L., de Felice G., de Santis S. (2015). A qualification method for externally bonded Fibre Reinforced Cementitious Matrix (FRCM) strengthening systems. Composites Part B: Engineering, 78, 497-506.

[56] Zhang X.B., Aljewifi H., Li J. (2013) Failure behavior investigation of continuous yarn reinforced cementitious composites. Construction and Building Materials, 47, 456-464.

[57] Ferreira S.R., Martinelli E., Pepe M., Silva F.A., Filho R.D.T. (2016) Inverse identification of the bon behavior for jute fibers in cementitious matrix. Composite Part B, 95, $440-452$.

[58] Dalalbashi A., Ghiassi B., Oliveira D.V., Freitas A. (2018) Effect of test setup on the fiber-to-mortar pull-out response in TRM composites: experimental and analytical modeling. Composites Part B, 143, 250-268.

[59] Banholzer B., Brameshuber, W., Jung W. (2005) Analytical simulation of pull-out tests. The direct problema. Cement and Concrete Composites, 27, 93-101.

[60] Banholzer, B. (2006) Bond of a strand in a cementitious matrix. Materials and Structures, $39,1015-1028$.

[61] Donnini J., Lancioni G., Corinaldesi V. (2018) Failure modes in FRCM systems with dry and pre-impregnated carbon yarns: Experiments and modeling. Composite Part B, 140, $57-67$. 
- Figure 1. Particle size distribution of the original and corrected soils

- Figure 2. Typical failure mode of rammed earth cylinder

- Figure 3. Typical failure mode of earth-based mortar

- Figure 4. Meshes tested in the experimental program: (a) glass fiber mesh (GM); (b) nylon mesh (NM)

- Figure 5. Direct tensile test scheme

- Figure 6. Linear force-axial strain curves obtained from the tensile tests: (a) glass fiber mesh (GM); (b) nylon mesh (NM)

- Figure 7. Direct tensile coupon test scheme

- Figure 8. Results of the direct tensile tests of the TCGM specimens: (a) linear forceaxial strain curves; (b) typical failure mode

- Figure 9. Results of the direct tensile tests of the TCNM specimens: (a) linear forceaxial strain curves; (b) typical failure mode

- Figure 10. Detail of stage I and stage II of the direct tensile tests for: (a) TCGM; (b) TCNM

- Figure 11. Comparison of the direct tensile tests on dry mesh and TRM coupon specimens: (a) TCGM; (b) TCNM

- Figure 12. Pull-out tests: (a) test setup; (b) observed failure modes

- Figure 13. Pull-out response curves of the POGM specimens: (a) displacement at the loaded end; (b) displacement at the free end 
- Figure 14. Results of the pull-out tests on the PONM specimens: (a) response curve considering the displacement at the loaded end; (b) boxplot maximum linear force as function of the bonded length

- Figure 15. Single-lap shear tests: (a) test setup; (b) observed failure modes

- Figure 16. Response curves of the SLGM specimens tested under single-lap shear considering: (a) displacement at the loaded end; (b) displacement at the free end

- Figure 17. Response curves of the SLNM specimens tested under single-lap shear considering: (a) displacement at the loaded end; (b) displacement at the free end

- Figure 18. Statistical analysis of the pull-out results from the POGM specimens considering the bonded length and: (a) maximum linear force; (b) linear force at sliding onset; (c) ultimate displacement at the loaded end; (d) ultimate displacement at the free end; (e) displacement at the loaded end for the maximum linear force; (f) linear force at the end of the elastic phase.

- Figure 19. Statistical analysis of the results from the single-lap shear test on the SLGM specimens considering the bonded length and: (a) maximum linear force; (b) linear force to onset sliding, (c) displacement at the loaded end for the maximum linear force (f) ultimate sliding.

- Figure 20. Comparison of the results from the different tests conducted on GM specimens in terms of: (a) maximum linear force; (b) linear force to onset sliding. 
- Table 1. Geotechnical properties of the original and corrected soils

- Table 2. Composition and properties of the earth-based mortars studied to define mortar EM2 (CoV is given inside parenthesis)

- Table 3. Physical properties of NM and GM meshes

- Table 4. Mechanical properties of the meshes ( $\mathrm{CoV}$ is reported inside parenthesis)

- Table 5. Results of pull-out tests on the POGM specimens

- Table 6. Results of pull-out tests on the PONM specimens

- Table 7. Results of single-lap shear tests on the SLGM specimens.

- Table 8. Results of single-lap-shear tests on the SLNM specimens.

- Table 9. Results of single-lap shear tests of the glass fiber mesh considering the failure mode 
This paper can be found at https://doi.org/10.1080/15583058.2019.1619881

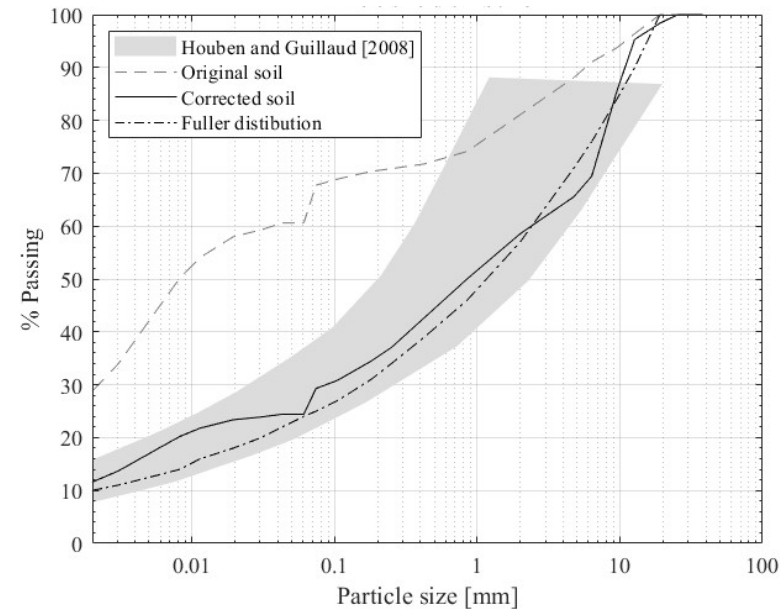

Figure 21. Particle size distribution of the original and corrected soils 


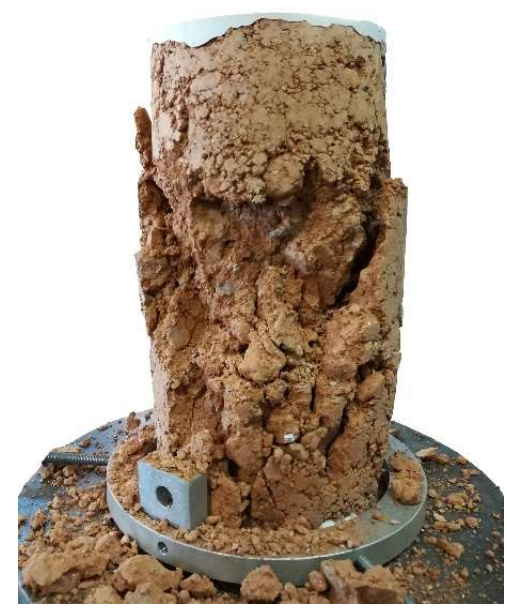

Figure 22. Typical failure mode of rammed earth cylinder 
This paper can be found at https://doi.org/10.1080/15583058.2019.1619881

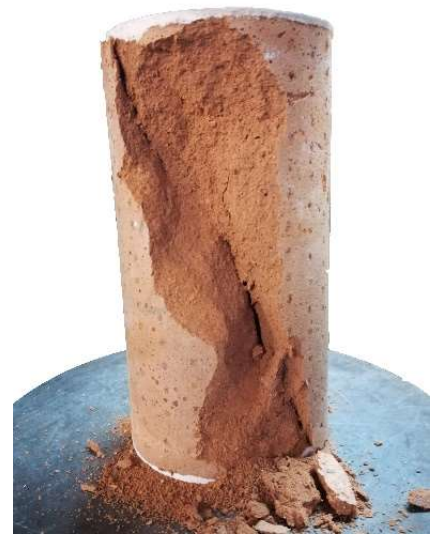

Figure 23. Typical failure mode of earth-based mortar 


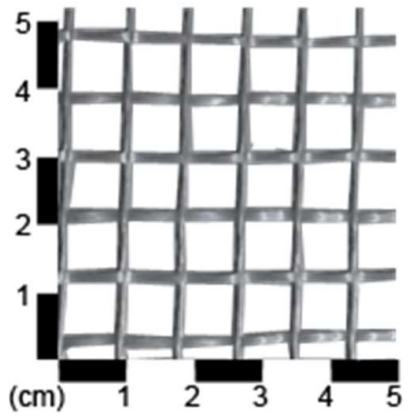

(a)

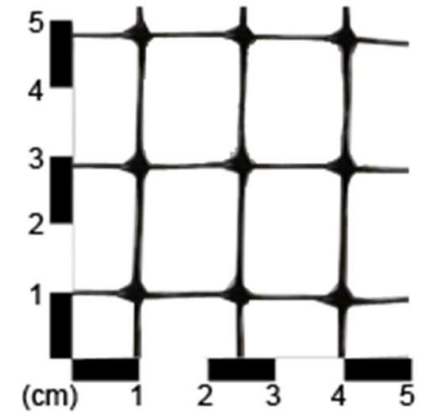

(b)

Figure 24. Meshes tested in the experimental program: (a) glass fiber mesh (GM); (b) nylon mesh (NM) 


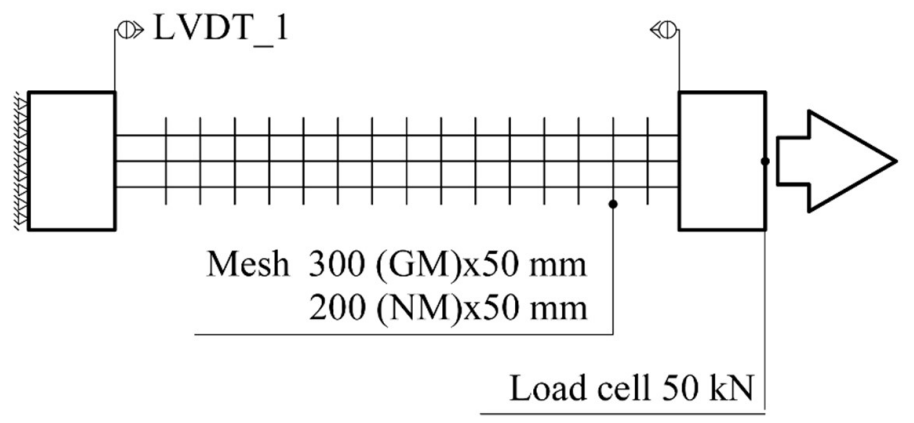

Figure 25. Direct tensile test scheme 
This paper can be found at https://doi.org/10.1080/15583058.2019.1619881

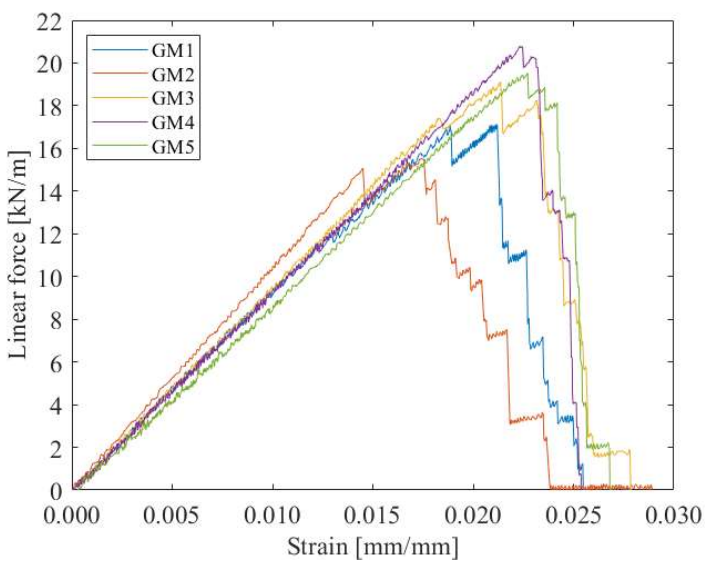

(a)

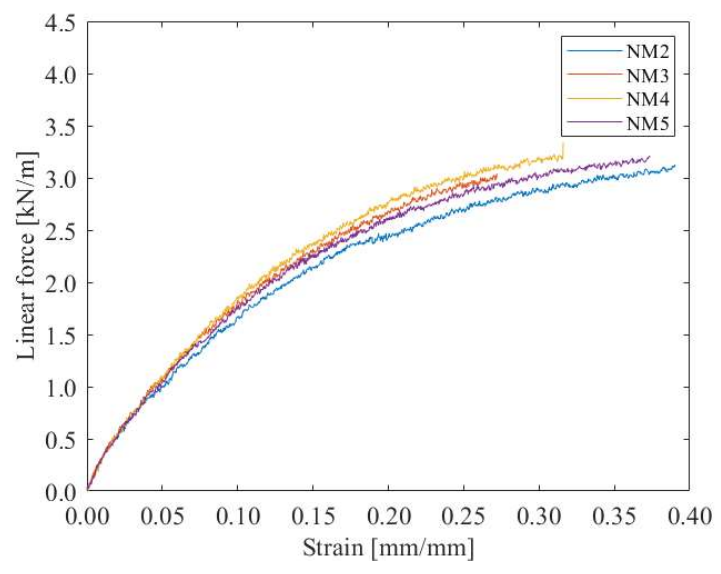

(b)

Figure 26. Linear force-axial strain curves obtained from the tensile tests: (a) glass fiber mesh (GM); (b) nylon mesh (NM) 


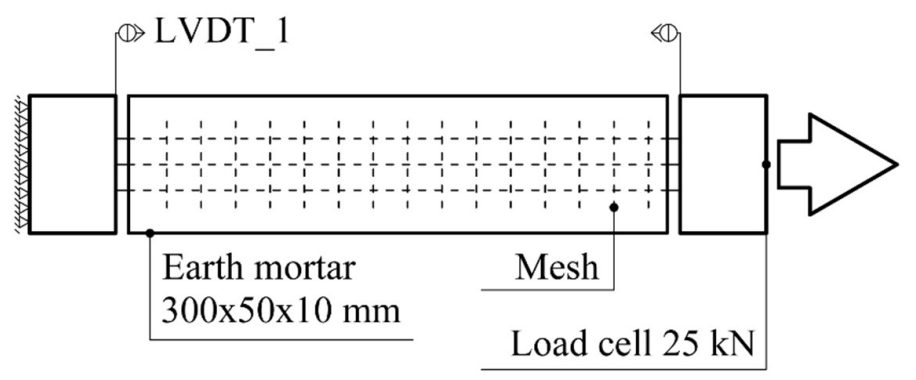

Figure 27. Direct tensile coupon test scheme 


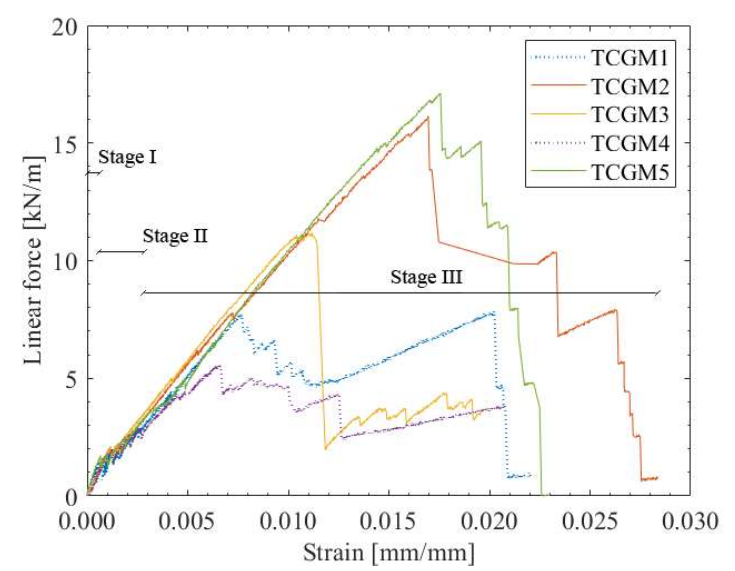

(a)

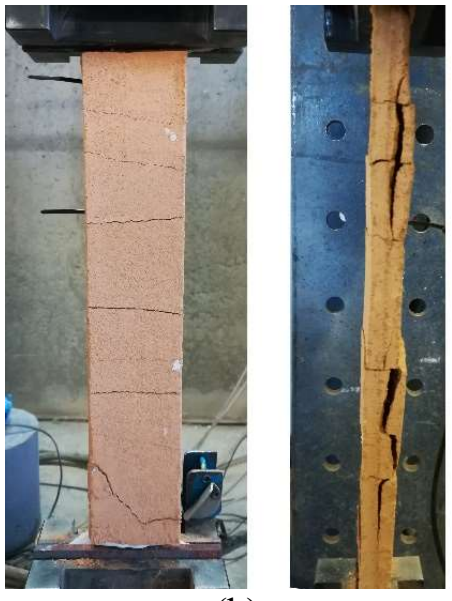

(b)

Figure 28. Results of the direct tensile tests of the TCGM specimens: (a) linear force-axial strain curves; (b) typical failure mode 
This paper can be found at https://doi.org/10.1080/15583058.2019.1619881

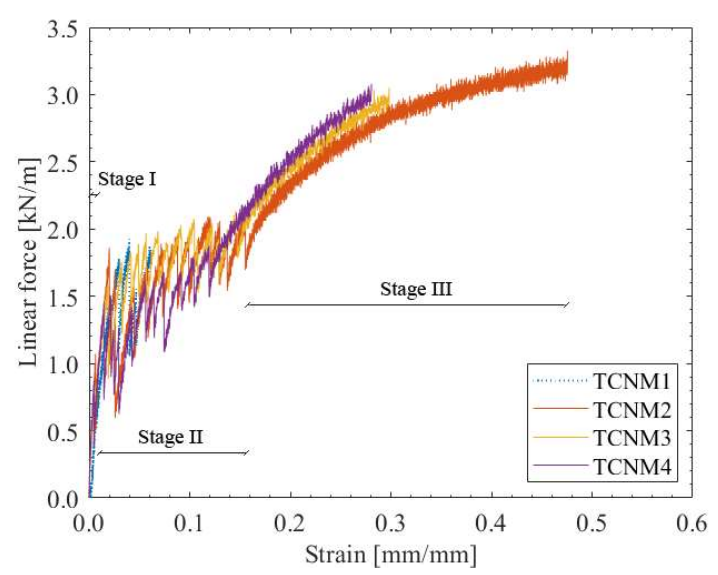

(a)

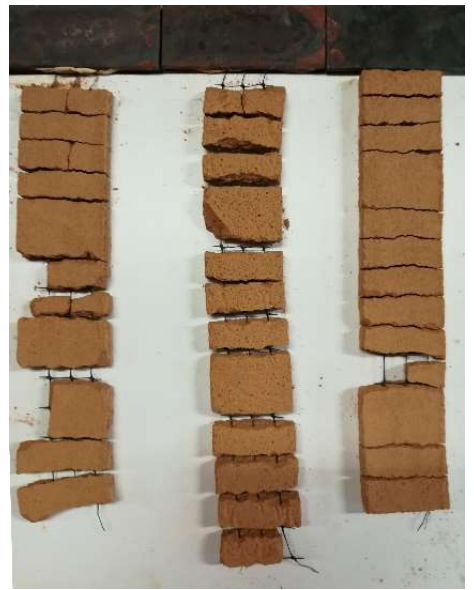

(b)

Figure 29. Results of the direct tensile tests of the TCNM specimens: (a) linear force-axial strain curves; (b) typical failure mode 
This paper can be found at https://doi.org/10.1080/15583058.2019.1619881

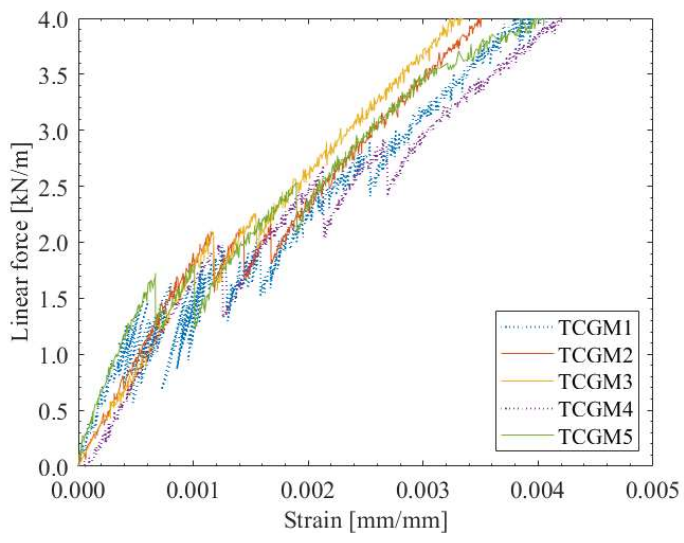

(a)

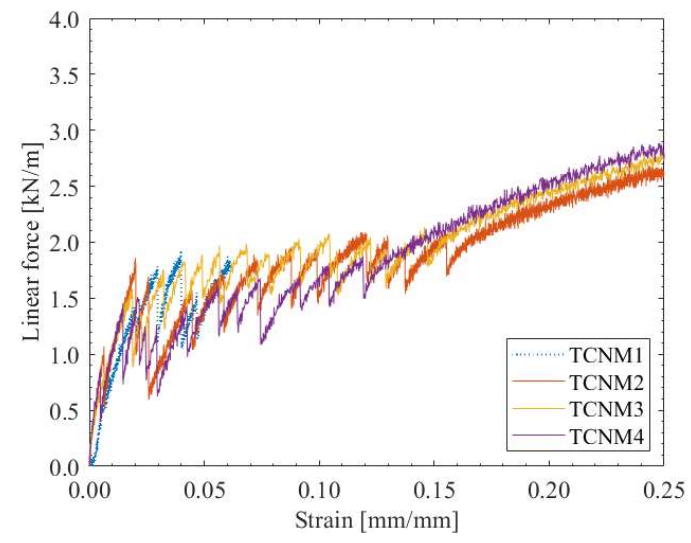

(b)

Figure 30. Detail of stage I and stage II of the direct tensile tests for: (a) TCGM; (b) TCNM 
This paper can be found at https://doi.org/10.1080/15583058.2019.1619881

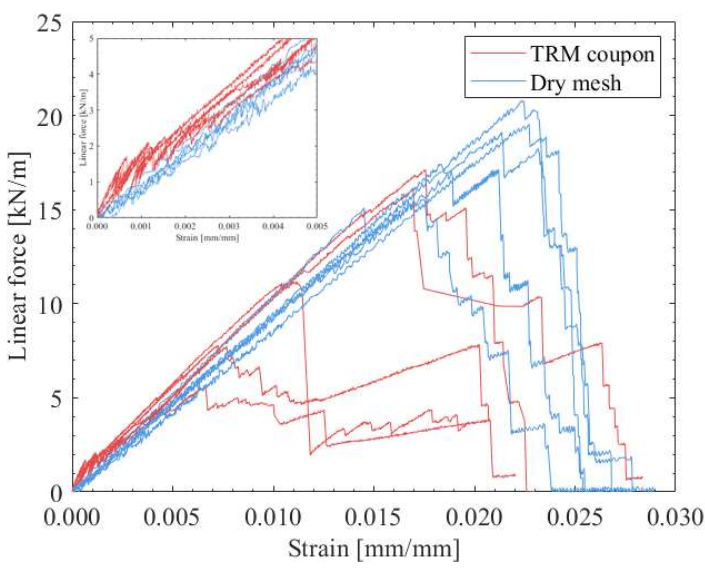

(a)

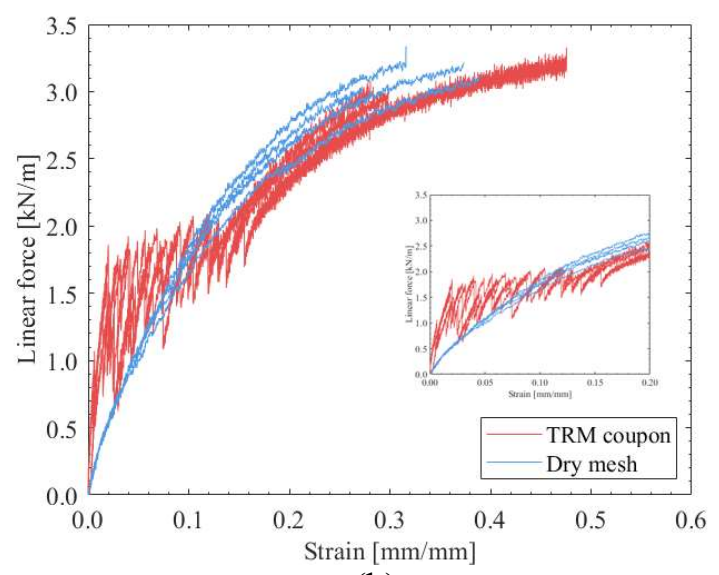

(b)

Figure 31. Comparison of the direct tensile tests on dry mesh and TRM coupon specimens:

(a) TCGM; (b) TCNM 


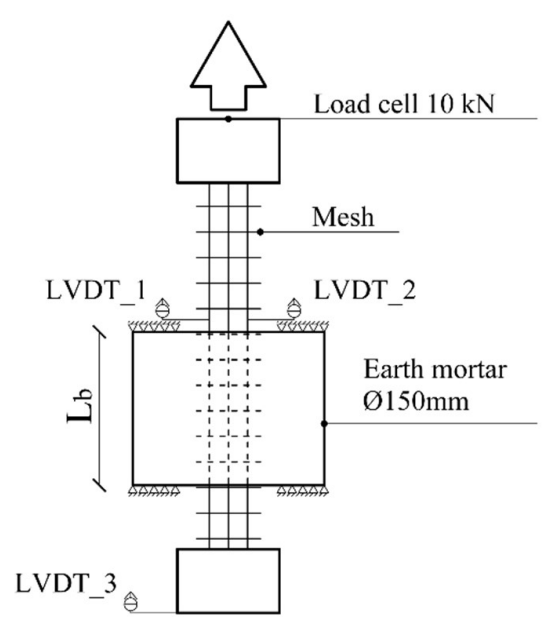

(a)

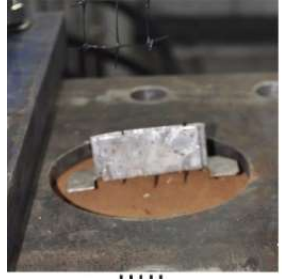

|||||

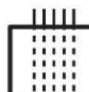

(1)
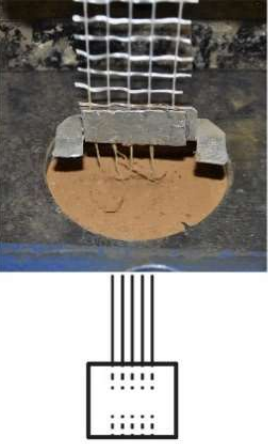

(2)

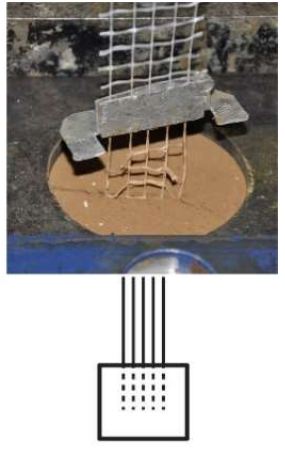

(3)

(b)

Figure 32. Pull-out tests: (a) test setup; (b) observed failure modes 


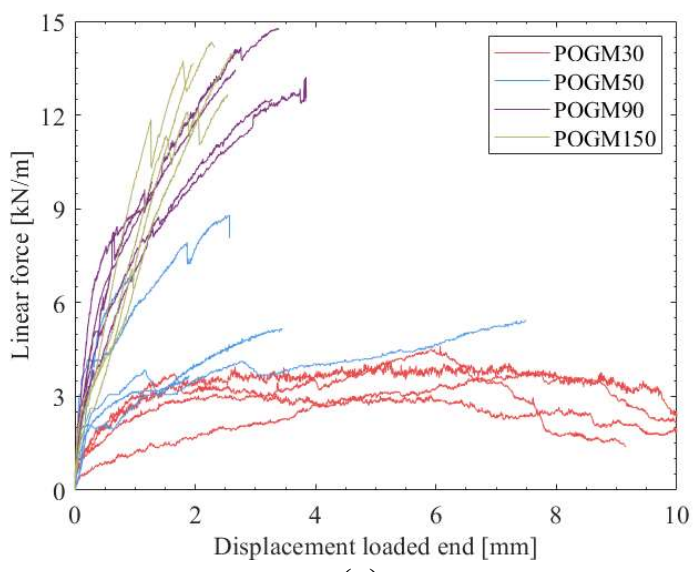

(a)

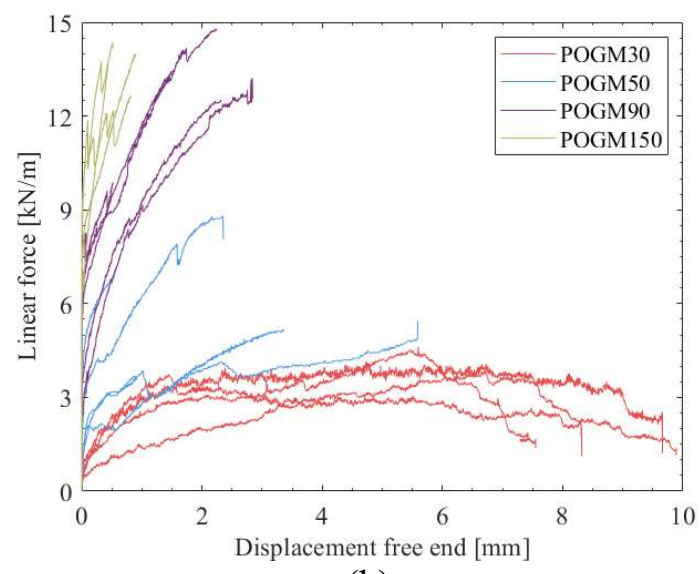

(b)

Figure 33. Pull-out response curves of the POGM specimens: (a) displacement at the loaded end; (b) displacement at the free end 


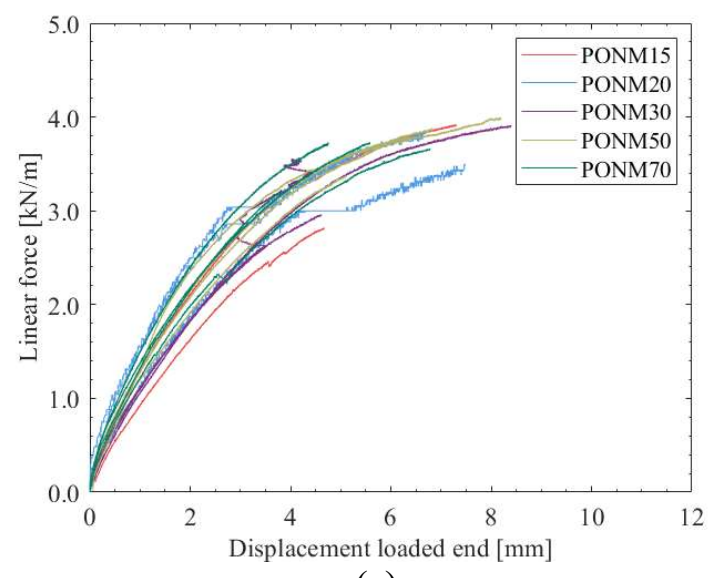

(a)

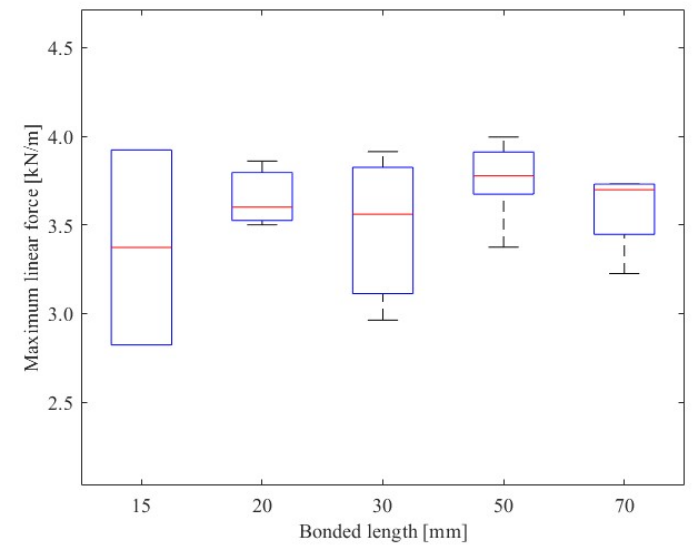

(b)

Figure 34. Results of the pull-out tests on the PONM specimens: (a) response curve considering the displacement at the loaded end; (b) boxplot maximum linear force as function of the bonded length 


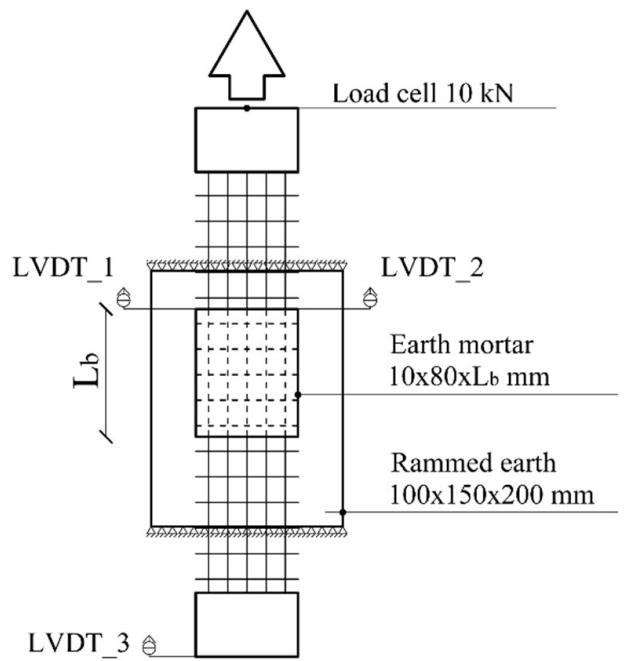

(a)

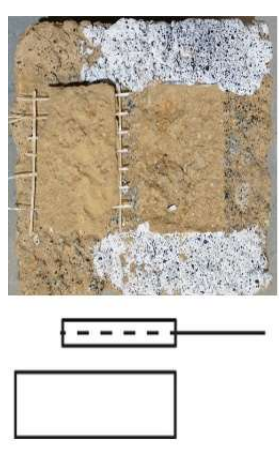

(1)

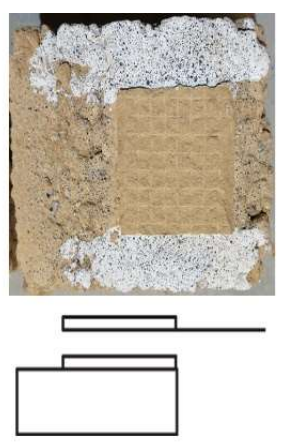

(2)

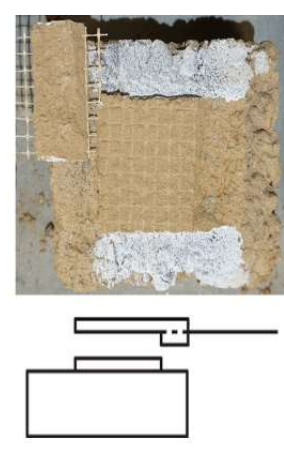

(3)

(b)

Figure 35. Single-lap shear tests: (a) test setup; (b) observed failure modes 


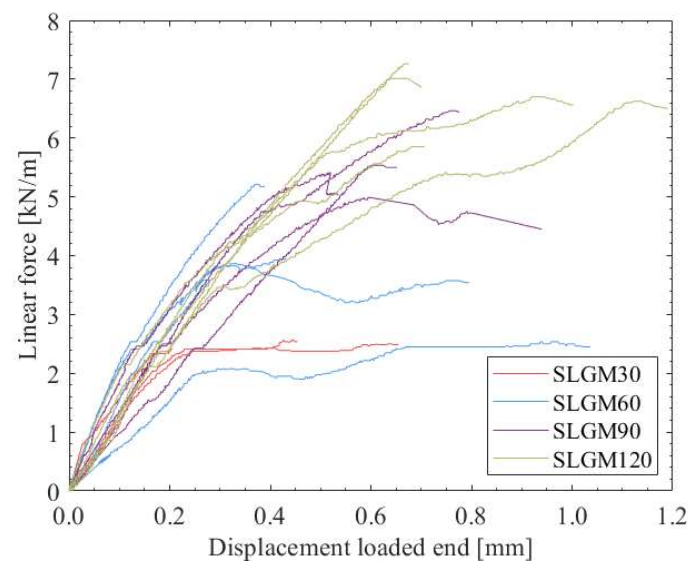

(a)

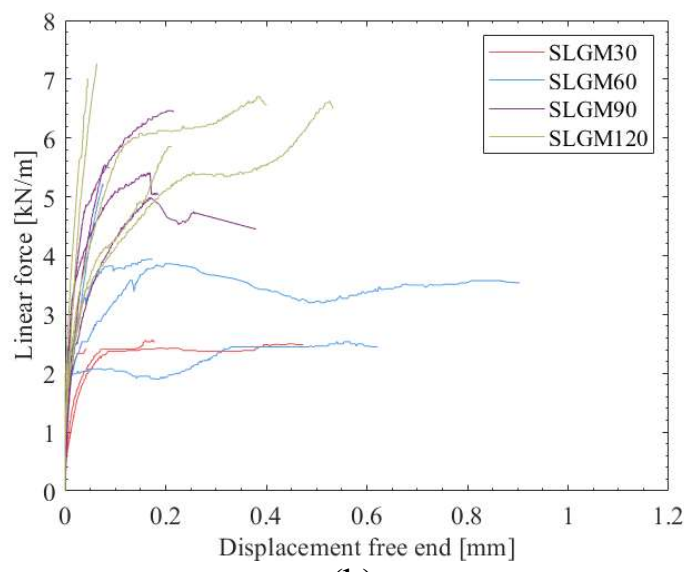

(b)

Figure 36. Response curves of the SLGM specimens tested under single-lap shear considering: (a) displacement at the loaded end; (b) displacement at the free end 
This paper can be found at https://doi.org/10.1080/15583058.2019.1619881

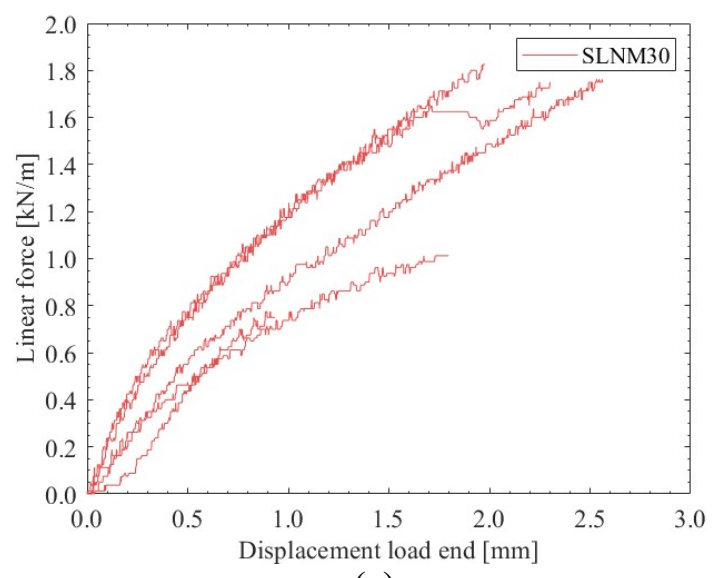

(a)

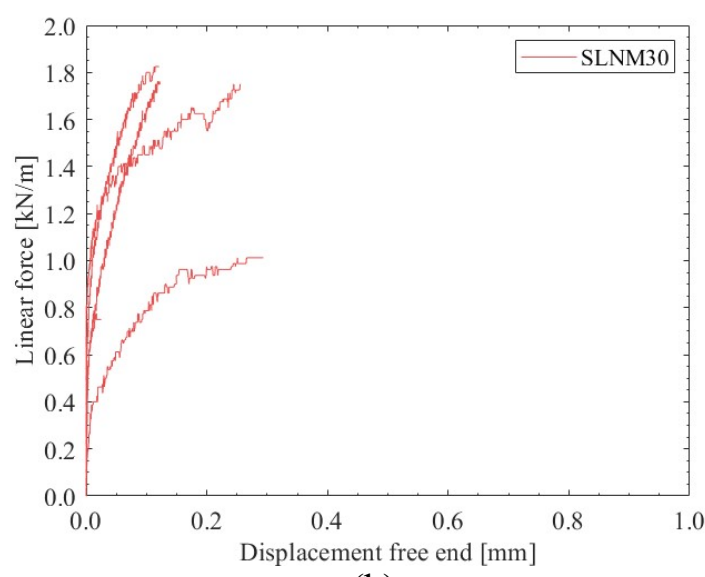

(b)

Figure 37. Response curves of the SLNM specimens tested under single-lap shear considering: (a) displacement at the loaded end; (b) displacement at the free end 


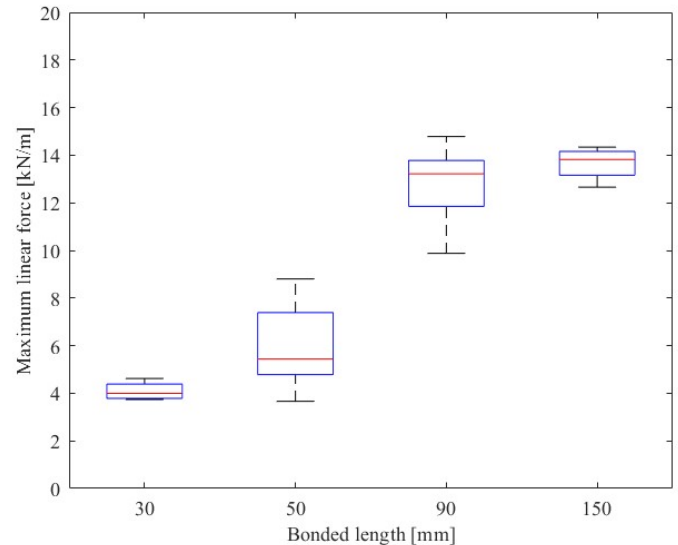

(a)

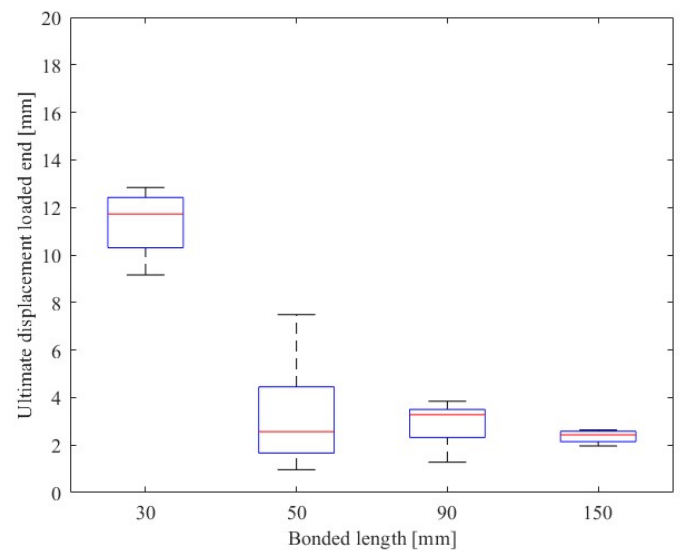

(c)

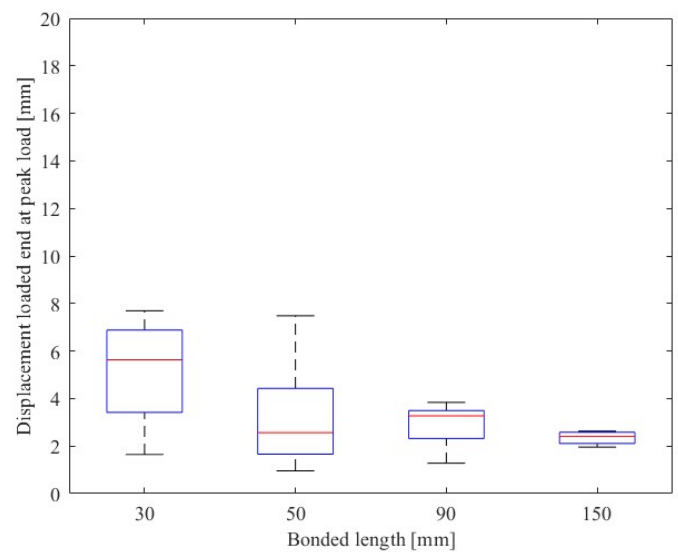

(e)

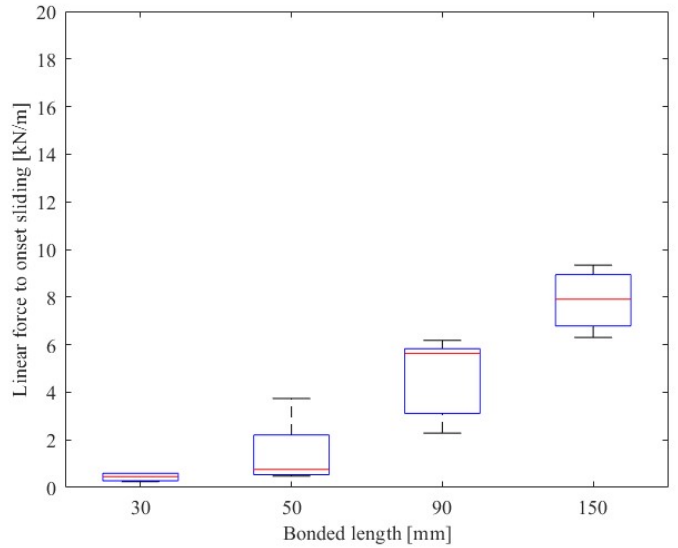

(b)

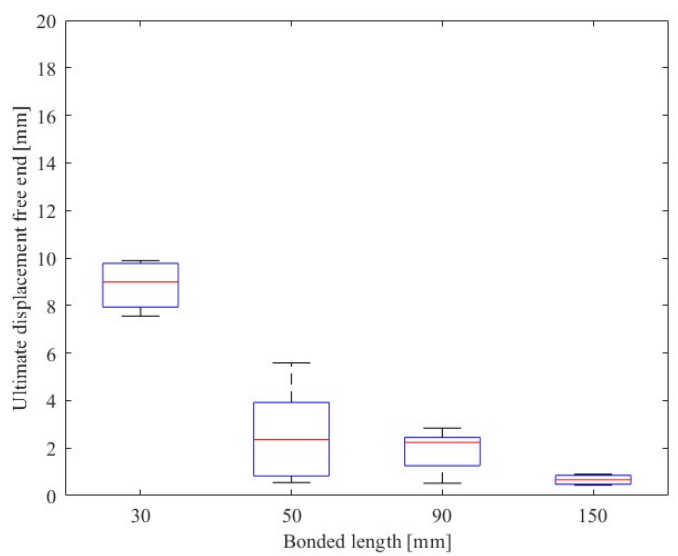

(d)

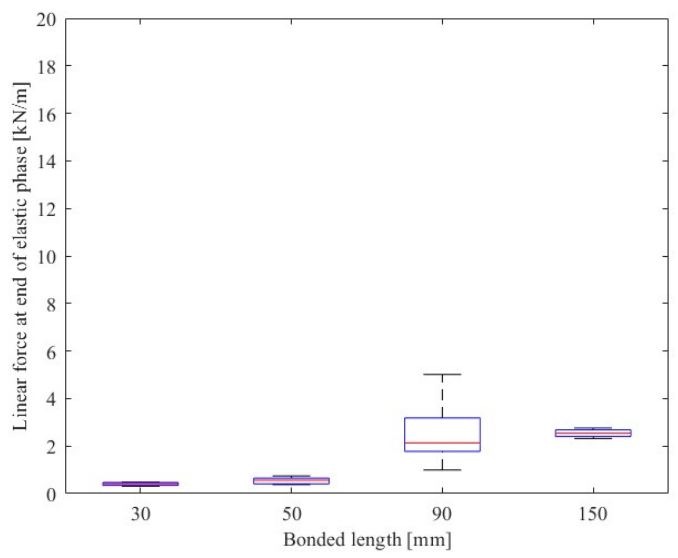

(f)

Figure 38. Statistical analysis of the pull-out results from the POGM specimens considering the bonded length and: (a) maximum linear force; (b) linear force at sliding onset; (c) 
This paper can be found at https://doi.org/10.1080/15583058.2019.1619881

ultimate displacement at the loaded end; (d) ultimate displacement at the free end; (e) displacement at the loaded end for the maximum linear force; (f) linear force at the end of the elastic phase. 


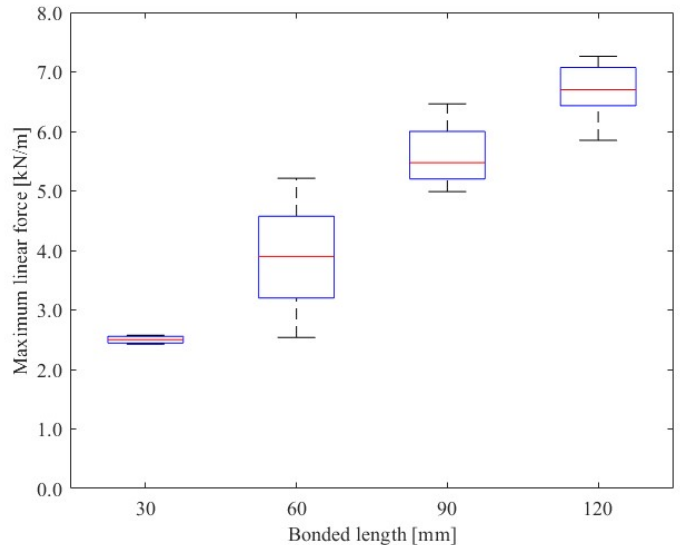

(a)

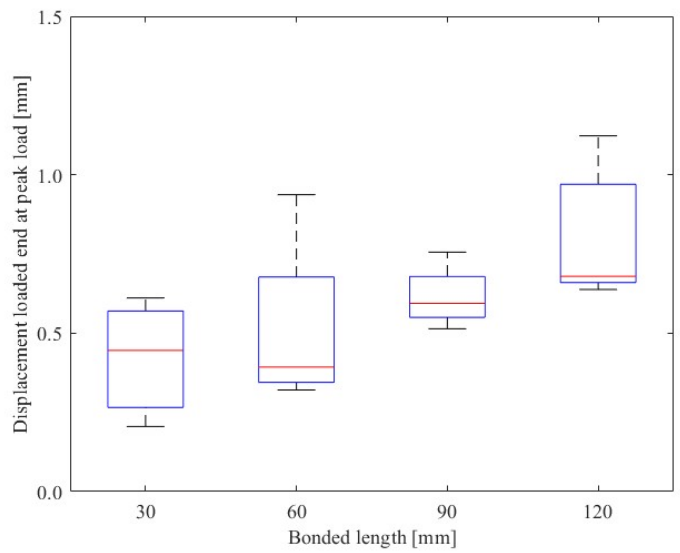

(c)

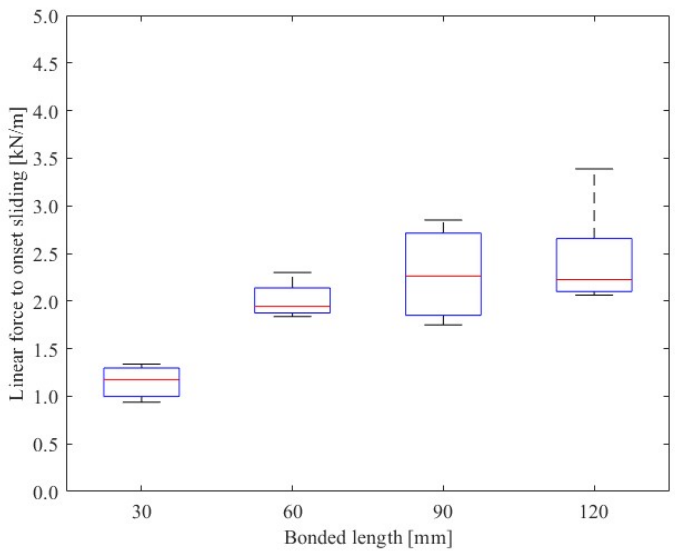

(b)

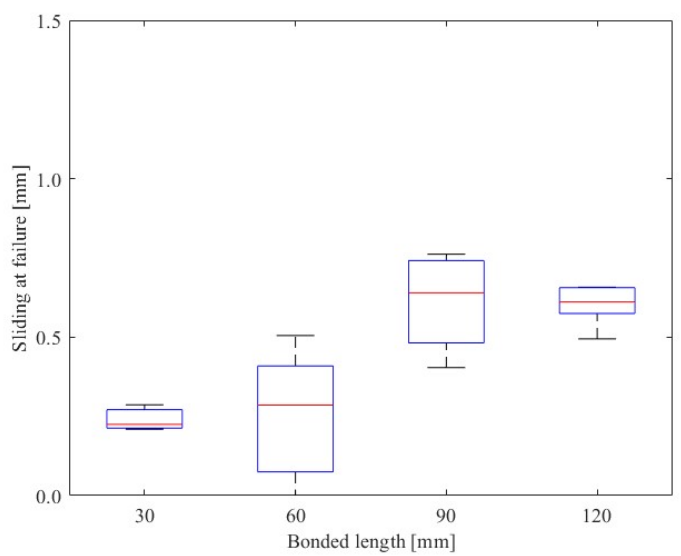

(d)

Figure 39. Statistical analysis of the results from the single-lap shear test on the SLGM specimens considering the bonded length and: (a) maximum linear force; (b) linear force to onset sliding, (c) displacement at the loaded end for the maximum linear force (f) ultimate sliding. 


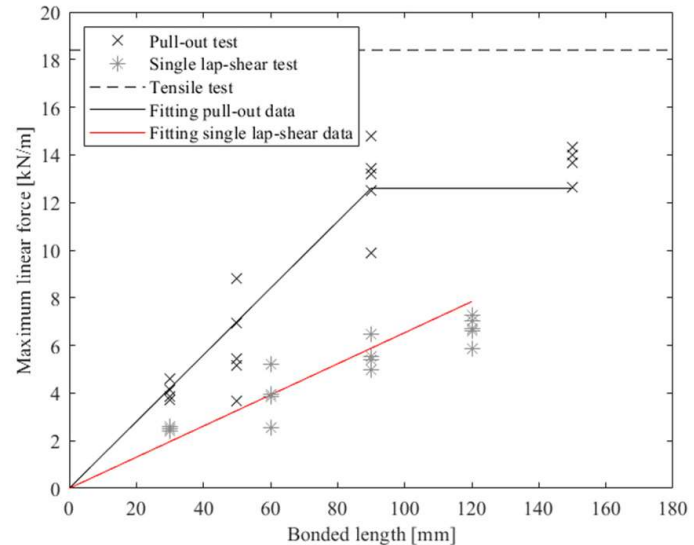

(a)

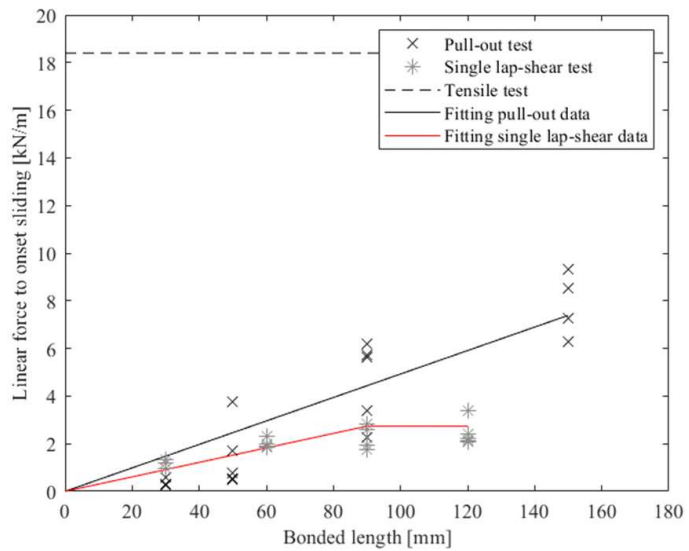

(b)

Figure 40. Comparison of the results from the different tests conducted on GM specimens in terms of: (a) maximum linear force; (b) linear force to onset sliding. 
This paper can be found at https://doi.org/10.1080/15583058.2019.1619881

Table 10. Geotechnical properties of the original and corrected soils

$$
\text { Soil Clay \% Silt \% Sand \% Gravel \% } \rho_{d}\left(\mathrm{~g} / \mathrm{cm}^{3}\right) \text { OWC (\%) LL (\%) PL (\%) }
$$

\begin{tabular}{lcccccccc}
\hline Original & 29 & 32 & 21 & 18 & 1.81 & 18 & 45 & 24 \\
\hline Corrected & 12 & 13 & 34 & 41 & 2.13 & 10 & 45 & 24
\end{tabular}

* Clay $<0.002 \mathrm{~mm} ; 0.002 \mathrm{~mm}<$ silt $<0.06 \mathrm{~mm} ; 0.06 \mathrm{~mm}<$ sand $<2 \mathrm{~mm} ; 2 \mathrm{~mm}<$ gravel 
This paper can be found at https://doi.org/10.1080/15583058.2019.1619881

Table 11. Composition and properties of the earth-based mortars studied to define mortar EM2 (CoV is given inside parenthesis)

\begin{tabular}{cccccccc}
\hline Mortar & \% Soil & $\%$ Sand & $\%$ Clay & W/S $(\%)$ & $f_{c}(\mathrm{MPa})$ & $f_{b}(\mathrm{MPa})$ & $S_{L}(\%)$ \\
\hline EM2.I & 25 & 75 & 9 & 17 & $0.77(6 \%)$ & $0.32(6 \%)$ & $1.3(0 \%)$ \\
\hline EM2.II & 30 & 70 & 11 & 18 & $0.87(7 \%)$ & $0.49(22 \%)$ & $2.0(0 \%)$ \\
\hline EM2.III & 35 & 65 & 12 & 19 & $1.25(7 \%)$ & $0.53(13 \%)$ & $3.0(0 \%)$ \\
\hline
\end{tabular}


This paper can be found at https://doi.org/10.1080/15583058.2019.1619881

Table 12. Physical properties of NM and GM meshes

\begin{tabular}{cccccccc}
\hline $\begin{array}{c}\text { Type of } \\
\text { mesh }\end{array}$ & $\begin{array}{c}\text { Price } \\
\left(€ / \mathrm{m}^{2}\right)\end{array}$ & $\begin{array}{c}\text { Mesh size } \\
(\mathrm{mm} \times \mathrm{mm})\end{array}$ & $\begin{array}{c}\text { TEX X } \\
(\mathrm{g} / \mathrm{km})\end{array}$ & $\begin{array}{c}\text { TEX Y } \\
(\mathrm{g} / \mathrm{km})\end{array}$ & $\begin{array}{c}\text { GSM } \\
\left(\mathrm{g} / \mathrm{m}^{2}\right)\end{array}$ & $\begin{array}{c}\rho \\
\left(\mathrm{g} / \mathrm{cm}^{3}\right)\end{array}$ & $\begin{array}{c}\mathrm{A}_{\text {yarn }} \\
\left(\mathrm{mm}^{2}\right)\end{array}$ \\
\hline $\mathrm{GM}^{*}$ & 0.85 & $8 \times 9$ & 471 & 424 & 93 & 1.610 & 0.29 \\
\hline $\mathrm{NM}^{*}$ & 0.63 & $16 \times 21$ & 765 & 874 & 63 & 0.897 & 0.97 \\
\hline
\end{tabular}

* Survey conducted in 2016 in Northern Portugal 
This paper can be found at https://doi.org/10.1080/15583058.2019.1619881

Table 13. Mechanical properties of the meshes ( $\mathrm{CoV}$ is reported inside parenthesis)

\begin{tabular}{ccccc}
\hline Mesh & $F_{w, p}(\mathrm{kN} / \mathrm{m})$ & $f_{t}(\mathrm{MPa})$ & $\varepsilon_{\text {peak }}(\mathrm{mm} / \mathrm{mm})$ & $E(\mathrm{MPa})$ \\
\hline $\mathrm{GM}$ & $18.42(11 \%)$ & $625.80(11 \%)$ & $0.021(10 \%)$ & $31981(6 \%)$ \\
\hline $\mathrm{NM}$ & $3.18(4 \%)$ & $54.37(4 \%)$ & $0.340(16 \%)$ & $361(4 \%)$ \\
\hline $\begin{array}{c}\text { Basalt } \\
\left(250 \mathrm{~g} / \mathrm{m}^{2}\right)\end{array}$ & 60 & - & 0.020 & 89000 \\
\hline $\begin{array}{c}\text { Alkali-resistant fiberglass } \\
\left(225 \mathrm{~g} / \mathrm{m}^{2}\right)\end{array}$ & 45 & - & 0.030 & - \\
\hline $\begin{array}{c}\text { Stainless steel } \\
\left(400 \mathrm{~g} / \mathrm{m}^{2}\right)\end{array}$ & 110 & - & 0.019 & 70000 \\
\hline
\end{tabular}


This paper can be found at https://doi.org/10.1080/15583058.2019.1619881

Table 14. Results of pull-out tests on the POGM specimens

\begin{tabular}{|c|c|c|c|c|c|c|c|c|c|c|c|}
\hline Spec. & $\begin{array}{c}F_{w, p} \\
(\mathrm{kN} / \mathrm{m})\end{array}$ & FM & Spec. & $\begin{array}{c}F_{w, p} \\
(\mathrm{kN} / \mathrm{m})\end{array}$ & FM & Spec. & $\begin{array}{c}F_{w, p} \\
(\mathrm{kN} / \mathrm{m})\end{array}$ & FM & Spec. & $\begin{array}{c}F_{w, p} \\
(\mathrm{kN} / \mathrm{m})\end{array}$ & $\mathrm{FM}$ \\
\hline 30_1 & 4.6 & 3 & $50 \_1$ & 6.9 & 2 & $90 \_1$ & 13.2 & 2 & 150_1 & 14.4 & 2 \\
\hline $30 \_2$ & $*$ & $*$ & $50 \_2$ & 5.2 & 2 & $90 \_2$ & 12.5 & 2 & $150 \_2$ & 13.7 & 2 \\
\hline $30 \_3$ & 3.7 & 3 & $50 \_3$ & $*$ & $*$ & $90 \_3$ & 9.9 & 2 & $150 \_3$ & 12.7 & 2 \\
\hline 30_4 & 3.8 & 3 & $50 \_4$ & 5.4 & 2 & 90_4 & 13.4 & 2 & $150 \_4$ & 14.0 & 2 \\
\hline $30 \_5$ & 4.2 & 3 & $50 \_5$ & 8.8 & 2 & $90 \_5$ & 14.8 & 2 & $150 \_5$ & 9.2 & 2 \\
\hline $\begin{array}{c}\text { Average } \\
(\mathrm{CoV})\end{array}$ & $\begin{array}{c}4.1 \\
(10 \%)\end{array}$ & & $\begin{array}{c}\text { Average } \\
(\mathrm{CoV})\end{array}$ & $\begin{array}{c}6.6 \\
(25 \%)\end{array}$ & & $\begin{array}{c}\text { Average } \\
(\mathrm{CoV})\end{array}$ & $\begin{array}{c}12.8 \\
(14 \%)\end{array}$ & & $\begin{array}{c}\text { Average } \\
(\mathrm{CoV})\end{array}$ & $\begin{array}{c}12.8 \\
(17 \%)\end{array}$ & \\
\hline
\end{tabular}

* Failure of the mortar. 
This paper can be found at https://doi.org/10.1080/15583058.2019.1619881

Table 15. Results of pull-out tests on the PONM specimens

\begin{tabular}{|c|c|c|c|c|c|c|c|c|c|c|c|c|c|c|}
\hline Spec. & $\begin{array}{c}F_{w, p} \\
(\mathrm{kN} / \mathrm{m})\end{array}$ & FM & Spec. & $\begin{array}{c}F_{w, p} \\
(\mathrm{kN} / \mathrm{m})\end{array}$ & FM & Spec. & $\begin{array}{c}F_{w, p} \\
(\mathrm{kN} / \mathrm{m})\end{array}$ & $\mathrm{FM}$ & Spec. & $\begin{array}{c}F_{w, p} \\
(\mathrm{kN} / \mathrm{m})\end{array}$ & FM & Spec. & $\begin{array}{c}F_{w, p} \\
(\mathrm{kN} / \mathrm{m})\end{array}$ & FM \\
\hline $15 \_1$ & 2.8 & 1 & $20 \_1$ & 3.9 & 1 & $30 \_1$ & 3.9 & 1 & $50 \_1$ & 4.0 & 1 & $70 \_1$ & 3.7 & 1 \\
\hline $15 \_2$ & $*$ & $*$ & $20 \_2$ & $*$ & $*$ & $30 \_2$ & 3.6 & 1 & $50 \_2$ & 3.8 & 1 & $70 \_2$ & 3.7 & 1 \\
\hline $15 \_3$ & 3.9 & 1 & $20 \_3$ & 3.6 & 1 & 30_3 & 3.0 & 1 & $50 \_3$ & 3.4 & 1 & $70 \_3$ & 3.2 & 1 \\
\hline \multirow[t]{2}{*}{$15 \_4$} & $*$ & $*$ & $20 \_4$ & $*$ & $*$ & & & & $50 \_4$ & 3.9 & 1 & $70 \_4$ & 3.7 & 1 \\
\hline & & & $20 \_5$ & 3.5 & 1 & & & & $50 \_5$ & 3.8 & 1 & & & \\
\hline $\begin{array}{c}\text { Average } \\
(\mathrm{CoV})\end{array}$ & $\begin{array}{l}3.4 \\
(-)\end{array}$ & & $\begin{array}{c}\text { Average } \\
(\mathrm{CoV})\end{array}$ & $\begin{array}{c}3.7 \\
(5 \%)\end{array}$ & & $\begin{array}{c}\text { Average } \\
(\mathrm{CoV})\end{array}$ & $\begin{array}{c}3.5 \\
(14 \%)\end{array}$ & & $\begin{array}{c}\text { Average } \\
(\mathrm{CoV})\end{array}$ & $\begin{array}{c}3.8 \\
(6 \%)\end{array}$ & & $\begin{array}{c}\text { Average } \\
(\mathrm{CoV})\end{array}$ & $\begin{array}{c}3.6 \\
(9 \%)\end{array}$ & \\
\hline
\end{tabular}

* Failure of the mortar. 
This paper can be found at https://doi.org/10.1080/15583058.2019.1619881

Table 16. Results of single-lap shear tests on the SLGM specimens.

\begin{tabular}{|c|c|c|c|c|c|c|c|c|c|c|c|}
\hline Spec. & $\begin{array}{c}F_{w, p} \\
(\mathrm{kN} / \mathrm{m})\end{array}$ & FM & Spec. & $\begin{array}{c}F_{w, p} \\
(\mathrm{kN} / \mathrm{m})\end{array}$ & FM & Spec. & $\begin{array}{c}F_{w, p} \\
(\mathrm{kN} / \mathrm{m})\end{array}$ & FM & Spec. & $\begin{array}{c}F_{w, p} \\
(\mathrm{kN} / \mathrm{m})\end{array}$ & FM \\
\hline $30 \_1$ & 2.45 & 1 & $60 \_1$ & 2.54 & 1 & $90 \_1$ & 4.99 & 2 & 120_1 & 7.01 & 2 \\
\hline $30 \_2$ & 2.95 & 2 & 60_2 & 3.86 & 2 & $90 \_2$ & 5.54 & 2 & $120 \_2$ & 5.85 & 3 \\
\hline $30 \_3$ & 2.58 & 2 & $60 \_3$ & 5.21 & 2 & $90 \_3$ & 5.41 & 2 & $120 \_3$ & 6.70 & 3 \\
\hline 30_4 & 2.43 & 1 & $60 \_4$ & 3.94 & 2 & $90 \_4$ & 4.68 & 2 & $120 \_4$ & 6.63 & 3 \\
\hline $30 \_5$ & 2.50 & 2 & $60 \_5$ & 3.93 & 1 & $90 \_5$ & 5.58 & 2 & $120 \_5$ & 7.26 & 2 \\
\hline $\begin{array}{c}\text { Average } \\
(\mathrm{CoV})\end{array}$ & $\begin{array}{l}2.58 \\
(8 \%)\end{array}$ & & $\begin{array}{c}\text { Average } \\
(\mathrm{CoV})\end{array}$ & $\begin{array}{c}3.90 \\
(24 \%)\end{array}$ & & $\begin{array}{c}\text { Average } \\
(\mathrm{CoV})\end{array}$ & $\begin{array}{l}5.24 \\
(7 \%)\end{array}$ & & $\begin{array}{c}\text { Average } \\
(\mathrm{CoV})\end{array}$ & $\begin{array}{l}6.69 \\
(8 \%)\end{array}$ & \\
\hline
\end{tabular}


This paper can be found at https://doi.org/10.1080/15583058.2019.1619881

Table 17. Results of single-lap-shear tests on the SLNM specimens.

\begin{tabular}{ccc}
\hline Spec. & $\begin{array}{c}F_{w, p} \\
(\mathrm{kN} / \mathrm{m})\end{array}$ & $\mathrm{FM}$ \\
\hline $30 \_1$ & 1.45 & 1 \\
\hline $30 \_2$ & 1.75 & 1 \\
\hline $30 \_3$ & 1.83 & 1 \\
\hline $30 \_4$ & 1.76 & 1 \\
\hline $30 \_5$ & 1.01 & 1 \\
\hline Average & 1.56 & \\
$(\mathrm{CoV})$ & $(21 \%)$ & \\
\hline
\end{tabular}


This paper can be found at https://doi.org/10.1080/15583058.2019.1619881

Table 18. Results of single-lap shear tests of the glass fiber mesh considering the failure mode

\begin{tabular}{cccccc}
\hline & FM & $F^{\prime}{ }_{w, p}$ & $F^{\prime}$ & $D^{\prime}{ }_{F w, p}$ & $S^{\prime}{ }_{u l t}$ \\
\hline SLG120 & 3 & $-5 \%(-8 \%)$ & $-14 \%(-474 \%)$ & $11 \%(-7 \%)$ & $-3 \%(23 \%)$ \\
\hline
\end{tabular}

